\title{
Monitoraggio quantitativo della valenza sul paesaggio degli elementi caratteristici, dei livellamenti e degli sbancamenti del suolo in un'area a vocazione vitivinicola, in relazione agli Standard di condizionalità 1.1 e 4.4 (Decreto MiPAAF n 30125/2009)
}

\author{
Paolo Bazzoffi \\ CREA-ABP, Consiglio per la Ricerca in Agricoltura e l'Analisi dell'Economia Agraria, Centro di Ricerca per \\ I'Agrobiologia e la Pedologia, Firenze, Italia
}

\begin{abstract}
Autore corrispondente: Paolo Bazzoffi
E-mail:paolo.bazzoffi@@crea.gov.it

Parole chiave: Paesaggio, condizionalità.

Ringraziamenti: Si ringrazia il Professore Arch. Roberto Barocchi, per i consigli forniti nell'applicazione dell'Analisi tassonomica Quantitativa.

Lavoro svolto nell'ambito del Progetto M0.NA.C0. (Rete di monitoraggio nazionale dell'efficacia ambientale della condizionalità e del differenziale di competitività da essa indotto a carico delle imprese agricole) finanziato dal Ministero delle Politiche Agricole, Alimentari e Forestali (MiPAAF) nell'ambito del Programma Rete Rurale Nazionale nel contesto dell'Azione 1.2.2 "Laboratori interregionali per lo sviluppo" del Programma Operativo denominato "Rete Rurale Nazionale 2007 - 2013 Coord. Paolo Bazzoffi".
\end{abstract}

\section{Riassunto}

Nell'attuale periodo di programmazione della PAC la protezione e il miglioramento delle infrastrutture gestite dalle aziende agricole e che contribuiscono grandemente alla determinazione della qualità del paesaggio rurale, compreso quelle ad alta valenza ecologica, sono state rese possibili rispettivamente dall'applicazione dello Standard di Condizionalità 4.4: "Mantenimento degli elementi caratteristici del paesaggio" e dall'adesione alla Misura agroambientale 323: "Tutela e riqualificazione del patrimonio rurale" implementata dai PSR.

In questo studio, che ha riguardato la valutazione paesaggistica di un'area del Comune di Conegliano, si è inteso fornire uno strumento su base geografica che, insieme ad altri strumenti di valutazione, consenta la redazione di carte tematiche di "monitoraggio quantitativo" della valenza degli elementi caratteristici del paesaggio e dell'impatto dei livellamenti, consentendo anche di rappresentarne la percezione dinamica. Il monitoraggio quantitativo può consentire alle Amministrazioni locali di trarre elementi di giudizio e di scelta idonei a tutelare gli aspetti paesistici dei distretti rurali ove l'attività vitivinicola gioca un ruolo fondamentale fra le attività economiche. Sulla base di tali elementi di giudizio e di scelta sarà possibile predisporre i regolamenti di governo del territorio, efficaci nella tutela del paesaggio, da far rispettare per l'ottenimento della concessione dell'autorizzazione, cui lo standard di Condizionalità 1.1.b fa riferimento.

Le metodologie proposta non sono alternative all'Approccio di Valutazione Storico Culturale (AVASC) proposto da Agnoletti (2010) che valuta la dinamica dell'uso del suolo e i cambiamenti avvenuti in un ampio arco temporale al fine di definire come "caratteristico" un elemento del paesaggio.
(C) Copyright P. Bazzoffi, 2015

Licenziatario PAGEPress, Italy

Italian Journal of Agronomy 2015; 10(s1):717

doi:10.4081/ija.2015.717

Questo articolo è distribuito secondo i termini della licenza Noncommercial Creative Commons Attribution (by-nc 3.0) che permette qualsiasi uso non commerciale, la distribuzione e la riproduzione con qualsiasi mezzo, a condizione che l'autore (autori) originale $(i)$ e la fonte siano accreditati.

\section{Introduzione}

Il DLgs 42/2004 (art. 131) definisce il paesaggio come una parte omogenea di territorio i cui caratteri derivano dalla natura, dalla storia umana 0 dalle reciproche interrelazioni e lo riconosce come identificativo del luogo; cioè come l'espressione di manifestazioni identitarie percepibili. Secondo Barocchi (2005) al concetto di paesaggio, come "forma dell'ambiente identificativo del luogo", va affiancato quello di buon paesaggio che, a fini programmatori, tiene conto delle qualità paesaggistiche delle varie parti di un territorio. Nella legislazione italiana di applicazione della PAC la protezione e il miglioramento delle infrastrutture gestite dalle aziende agricole e che contribuiscono grandemente alla determinazione della qualità del paesaggio rurale, compreso quelle ad alta valenza ecologica, sono state rese possibili rispettivamente dall'applicazione dello Standard di Condizionalità 4.4²: "Mantenimento degli elementi caratteristici del paesaggio" e dall'adesione alla Misura agroambientale 323: "Tutela e riqualificazione del patrimonio rurale" implementata dai PSR (sottomisura 4.4 nella programmazione 2014-2020). Sempre secondo Barocchi (2005) anche la morfologia del territorio contribuisce alla tipicità del paesaggio. Pertanto, il continuo estendersi delle superfici interessate dai livellamenti con bulldozer, in ambiente agricolo collinare, può determinane una modificazione profonda del paesaggio oltre ad indurre seri danni all'ecosistema (Bazzoffi e Tesi, 2011; Bazzoffi e Gardin, 2011; Agnoletti et al., 2011). Lo Standard di Condizionalità 1.1b che introduce il "Divieto di effettuare livellamenti non autorizzati" potrebbe ottenere un'azione benefica sul paesaggio se ponesse al centro dell'attenzione la necessità di pianificare questi interventi in modo rispettoso dell'ambiente. Purtroppo però, lo standard risulta scarsamente efficace 
(Bazzoffi e Tesi, 2011) perché è annoverato fra gli obblighi per il raggiungimento delle BCAA (Buone Condizioni Agronomiche e Ambientali) puntando alla riduzione dalla sola minaccia dall'erosione idrometeorica del suolo; mentre invece i rischi più importanti determinati dai livellamenti sono a carico non solo della superficie del suolo ma dell'intero profilo e della morfologia dei versanti, impattando sul paesaggio. L'obbligo per l'agricoltore, ai fini del rispetto della Condizionalità è unicamente all'ottenimento dell'autorizzazione da parte della PA prima di effettuare i rimodellamenti dei versanti, presupponendo che le normative locali di governo del territorio, cui l'autorizzazione è sottoposta, dettino regole efficaci per il raggiungimento degli obbiettivi di tutela ambientale.

L'analisi proposta in questo studio ha prodotto una metodologia per la redazione di carte tematiche di "monitoraggio quantitativo" della valenza degli elementi caratteristici del paesaggio e dell'impatto dei livellamenti, consentendo anche di rappresentarne la percezione dinamica. La metodologia non è alternativa all'Approccio di Valutazione Storico Culturale (AVASC) proposto da Agnoletti (2010) che valuta la dinamica dell'uso del suolo e i cambiamenti avvenuti in un ampio arco temporale al fine di definire come "caratteristico" un elemento del paesaggio. Il monitoraggio quantitativo può consentire alle Amministrazioni locali di trarre elementi di giudizio e di scelta idonei a tutelare gli aspetti paesistici dei distretti rurali ove l'attività vitivinicola gioca un ruolo fondamentale fra le attività economiche. Sulla base di tali elementi di giudizio e di scelta sarà possibile predisporre i regolamenti di governo del territorio, efficaci nella tutela del paesaggio, da far rispettare per l'ottenimento della concessione dell'autorizzazione, cui lo standard 1.1.b fa riferimento.

\section{Strumenti di valutazione del paesaggio del vino}

\section{Premessa}

Gli strumenti di valutazione del paesaggio prodotti nel presente studio tengono conto dei principi fondamentali contenuti nella Carta del Paesaggio del Vino, messa a punto a Cividale del Friuli nel 2001. Questo importante documento, in linea con la Convenzione Europea del Paesaggio del 2000 (ratificata con Legge del 2 gennaio 2006), rappresenta un punto di convergenza di vedute e di intenti tecnici fra viticultori, agronomi, amministratori, architetti e specialisti del paesaggio; categorie spesso contrapposte che operano nel settore vitivinicolo. Essa consente lo sviluppo di una nuova sensibilità, basata sul fatto che per rimanere nel mercato, non basta più produrre vino ma occorre produrre anche paesaggio.

La Carta, riportata per esteso in Appendice 1, propone regole per un buon "paesaggio del vino" basate su evidenze di diversa natura. Di queste si ritiene importante richiamarne alcune, in modo conciso, per la comprensione della metodologia applicata nel presente studio: 1) il paesaggio è un bisogno sociale in relazione all' aumento di disponibilità di tempo libero e del bisogno di cultura, 2) il valore delle produzioni legate al benessere e al tempo libero è legato anche alla qualità del paesaggio; pertanto non basta produrre vino. I viticoltori devono contribuire a produrre paesaggio curando che il territorio in cui operano mantenga e rafforzi i caratteri di qualità formale e di identità storica che sono necessari complementi della cultura. 3) Un buon paesaggio deve essere bello e quindi armonioso e ordinato, ma non monotono e deve essere identificativo del luogo e quindi contenere dei caratteri tradizionali 0 anche moderni, ma che con la tradizione hanno continuità e armonia. 4) Non basta applicare ai vigneti alcune regole per dare loro un aspetto armonioso: occorre che anche le altre parti di un territorio vitivinicolo abbiano un aspetto piacevole e identificativo. 5) Vanno conservati e recuperati gli elementi dell'architettura rurale, segni e radici della cultura contadina. 6) Nella localiz- zazione e realizzazione dei vigneti bisogna rispettare criteri che contemperino le necessità produttive con le esigenze di buon paesaggio integrando i vigneti con gli elementi vegetali del paesaggio quali boschetti, siepi e filari. 7) I terrazzamenti devono seguire la forma del terreno e le curve di livello, evitando linee spezzate. 8) Si devono evitare pesanti sbancamenti e, compatibilmente con le esigenze produttive, si devono mantenere gli elementi della morfologia e dell'idrografia, anche evitando di eliminare impluvi e ruscelli e lasciando attorno a questi fasce di vegetazione spontanea.

In questo studio, che ha riguardato la valutazione paesaggistica di un'area del Comune di Conegliano, si è inteso fornire uno strumento su base geografica che, insieme ad altri strumenti di valutazione, consenta l'acquisizione di elementi di informazione utili al giudizio complessivo ed alle scelte da attuare. Partendo dal tentativo di valutazione della qualità del paesaggio, ci si è resi conto che importante è la qualità percepita dello stesso. Si è seguito la scuola percettivista che definisce il paesaggio come "l'insieme delle forme di un luogo e delle relazioni fra di esse". In modo particolare si è adottato la definizione di Barocchi (2005) secondo il quale "il paesaggio è la forma dell'ambiente", in quanto ne rappresenta l'aspetto visibile. Sempre secondo Barocchi: "Il giudizio che diamo di un paesaggio o di un suo elemento, dipende molto dalla nostra cultura, ma anche dal fatto che quel paesaggio o elemento ci sia familiare 0 no; uno stesso paesaggio può piacere se vi siamo abituati e non piacere se risulta modificato rispetto al precedente, per un processo mentale di acquisizione o "familiarizzazione".

Basandoci su questo fondamentale presupposto, la valutazione del paesaggio di Conegliano ha impiegato un panel di esperti locali; per cui il prodotto dell'applicazione di tale metodologia è stata una carta della classificazione del valore panoramico come percepito dalla popolazione locale "culturalmente" adeguata ad esprimere un giudizio sul loro "paesaggio della vite e del vino". Si è cercato di individuare una corrispondenza tra ambiente ed il comune apprezzamento dello stesso, fornendo alle amministrazioni ed ai viticultori uno strumento che consenta di stabilire quanto alcuni interventi sul territorio, quali i livellamenti del terreno, determinino un turbamento nell'aspetto visibile percepito dal pubblico, che è il fruitore del paesaggio sia in quanto turista sia in quanto abitante, e che associa al vino l'insieme dei valori percepiti, siano essi positivi o negativi, acquisendone una impronta mentale e culturale.

Lo studio è proseguito con un'analisi dell'eterogeneità superficiale dei patch per le sue conseguenze sulla biodiversità e quindi sul "territorio del vino", scegliendo indici appropriati a rappresentare i concetti di base della quantificazione dei pattern del landscape. Infine, si è determinato l'impatto degli sbancamenti sulla "risorsa suolo" su un campione di vigneti di recente costituzione, situati nell'area di Conegliano di Valdobbiadene e di Asolo, sia su impianti a rittochino che a traverso, per mezzo della valutazione degli spessori di scavo e riporto.Si è infine proposta una metodologia originale per l'individuazione delle aree che hanno subito sbancamento, al fine di quantificare l'influenza di queste pratiche agronomiche nella modificazione "massiva" del paesaggio alle diverse scale geografiche e amministrative.

Nell'appendice 2 si suggeriscono direttive per l'effettuazione di sbancamenti e rimodellamenti dei versanti per l'impianto di vigneti ed altre colture arboree specializzate che, se venissero adottate dalle P.A., consentirebbero di garantire il mantenimento delle funzioni del suolo e del paesaggio.

\section{Classificazione tassonomica-quantitativa del paesaggio}

Assegnare un valore paesaggistico ad un territorio rurale non è compito facile. In questo studio si è seguito il metodo proposto da Barocchi 
(2005), adattato alla realtà del territorio in esame, che consiste nell'operare una classificazione tassonomico - qualitativa assegnando a priori dei valori paesaggistici alla geomorfologia (acclività elevata, acclività moderata, pianura) e all'uso del suolo: vari tipi di edificato, vari tipi di coltivi, di bosco, ecc.). Una volta assegnati i valori, la somma dei punteggi del valore paesaggistico morfologico e del valore paesaggistico di uso del suolo ha consentito l'elaborazione automatica di carte del valore paesistico. Secondo Barocchi (2005) il valore paesaggistico può essere distinto in quattro categorie: le parti di valore eccezionale, quelle di elevato valore, di comune valore ed infine, le parti degradate.

Il primo passo è stato l'elaborazione di una carta dell'uso del suolo di estremo dettaglio 1:1000. Essa è stata prodotta fotointerpretando le foto aeree riprese a bassa quota di un'area ad ovest dell'abitato di Conegliano. Il rilievo fotogrammetrico è stato effettuato da Aerocentro Varesino s.r.l. con un aeromobile a motore ad una velocità di $120 \mathrm{~km} / \mathrm{h}$. La macchina fotografica ha utilizzato un obbiettivo Nikkor AFS 28:70 D ed ha eseguito un scatto ogni 10 secondi con una risoluzione di 14 mega pixel. Ogni scatto ha incluso un'area di $600 \mathrm{mt}$ di larghezza e 450 mt di altezza al suolo. Lo spazio percorso ad ogni scatto nel senso della direzione di sorvolo è stato di 333 metri, quindi la sovrapposizione tra uno scatto e l'altro è stata del $26 \%$ dell'area di scatto, lungo una singola strisciata. Dopo aver georeferenziato e mosaicato le foto aeree si è proceduto alla fase di fotointerpretazione delle classi di uso del suolo. Ogni elemento del territorio riconoscibile da foto aerea con area maggiore di
0,25 ha e rappresentabile tramite poligoni è stato cartografato (Figura 1). E' stata così compilata una legenda di usi del suolo ed elementi caratteristici del territorio come riportato nella Tabella 1.

La fase successiva è consistita nell'effettuare un rilievo fotografico a terra di ogni tipologia di elementi costituenti il paesaggio, individuati da foto aerea. Gli elementi del paesaggio sono stati poi sottoposti ad un panel di 30 persone qualificate (amministratori locali, viticoltori, studenti universitari, docenti ecc.), scelto tra gli abitanti della zona, che hanno assegnato, ad ognuno di essi, un voto paesaggistico compreso fra 1 a 6 . Per l'attribuzione del valore a ciascun elemento del paesaggio è stata seguita una procedura originale. È stata realizzata una presentazione PowerPoint che conteneva almeno tre foto per ciascun elemento del paesaggio. È stato spiegato al panel che le foto servivano unicamente ad evocare alla memoria quegli elementi del paesaggio familiari e da tutti conosciuti nell'area in esame. Pertanto gli esperti non dovevano dare un valore alle singole foto. Esse avevano l'unico scopo di esemplificare visivamente il tipo di elemento del paesaggio che di volta in volta doveva essere valutato.

A titolo di esempio si riportano le tre Figure (dalla 2 alla 4, più Figura 5 a chiusura) utilizzate per la valutazione della tipologia "vigneti a rittochino" e le tre Figure (dalla 6 alla 8 , più Figura 9 a chiusura) utilizzate per dare un giudizio sul fattore morfologico "pendenza". Riguardo a questo ultimo fattore si è preferito utilizzare la medesima fotografia, artificialmente deformata, al fine di non introdurre elementi di perturbazione del giudizio causati da paesaggi diversi.

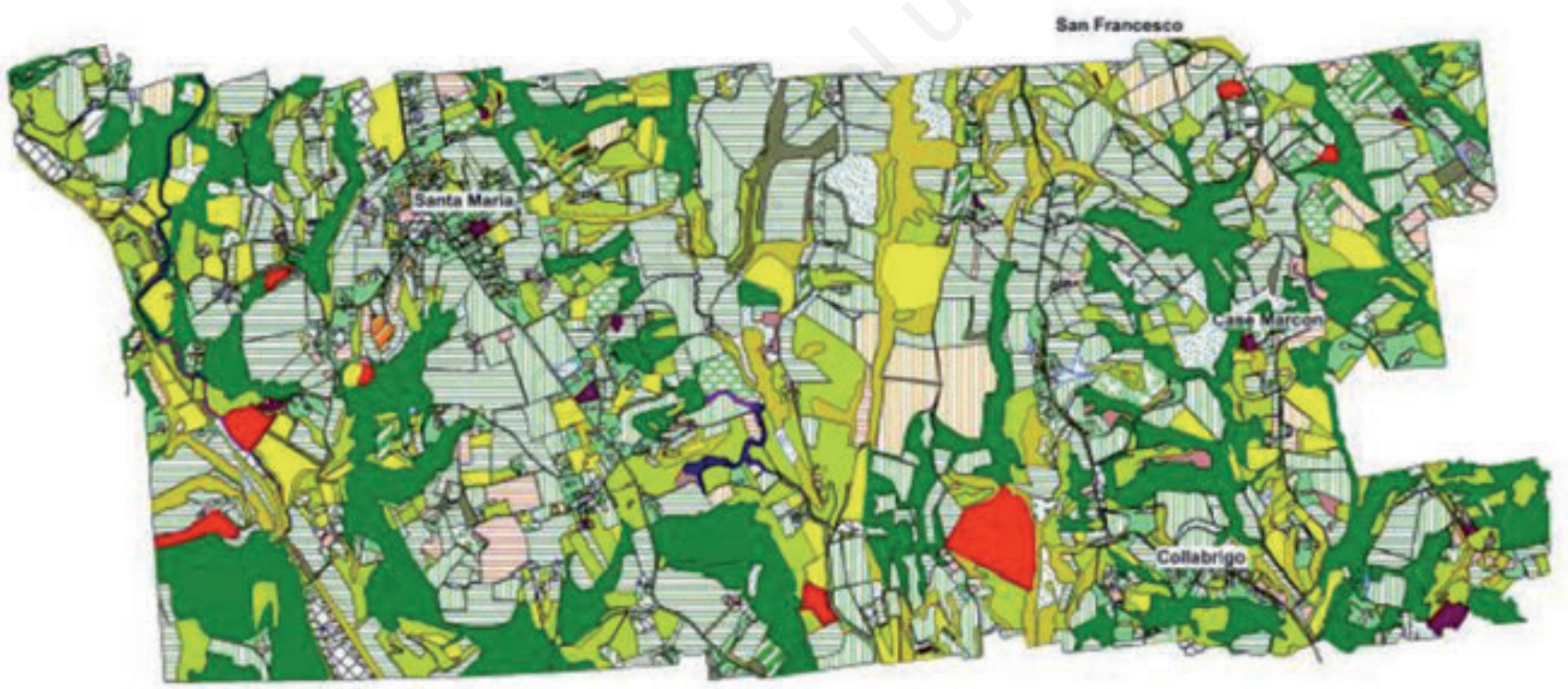

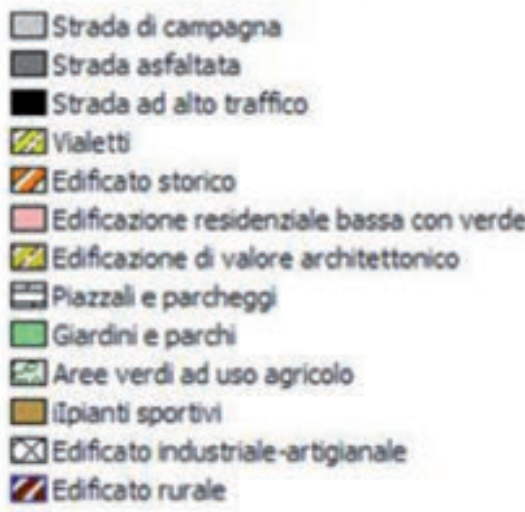

Figura 1. Carta dell'uso del suolo nell'area di studio (nel comune di Conegliano).

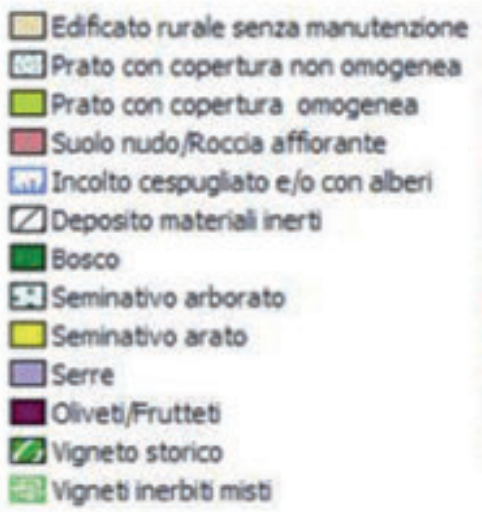


Ciascuna fotografia è stata mostrata per circa 5 secondi. Dopo ciascuna sequenza (relativa ad una singola categoria) è stata mostrata l'immagine "Stop" (per un tempo di riflessione di circa 10 secondi, necessario ad esprimere il giudizio. I tempi sono stati volutamente rapidi, al fine di cogliere la prima impressione che le foto evocavano nella mente degli esperti. La Figura 10 riporta la scheda di votazione somministrata al panel.

Oltre alle classi di uso del suolo è stato assegnato un punteggio ai valori paesaggistici delle classi morfologiche relative alla pendenza. Rispetto alla metodologia originale proposta da Barocchi si è voluto introdurre anche la valutazione paesaggistica della dimensione dei patch, in quanto è noto che il valore estetico è fortemente influenzato dalla frammentazione. Riguardo a questa importante proprietà, al panel di esperti è stato richiesto un giudizio paesaggistico su appezzamenti monocolturali di "piccole dimensioni" e di "grandi dimensioni". Non è stata sottoposta a giudizio la "dimensione media" in quanto

Tabella 1. Valori assegnati dal panel agli elementi del paesaggio (media, della mediana e media standardizzata). Gli elementi del paesaggio sono disposti in ordine decrescente di punteggio medio standardizzato.

\begin{tabular}{|c|c|c|c|c|}
\hline Classe & Cod_uso & Media & Mediana & Media standardizzata \\
\hline Vigneto storico & 1731 & 5,13 & 5 & 1,09 \\
\hline Vigneto inerbito a traverso & 1733 & 4,96 & 5 & 1,00 \\
\hline Aree con pendenze accentuate & 104 & 4,88 & 5 & 0,95 \\
\hline Edificato storico & 1011 & 4,83 & 5 & 0,93 \\
\hline Bosco & 152 & 4,75 & 5 & 0,88 \\
\hline Aree monocolturali di piccole dimensioni & 101 & 4,67 & 5 & 0,83 \\
\hline Oliveti/Frutteti & 172 & 4,46 & 4 & 0,71 \\
\hline Alberi isolati & 20 & 4,42 & 5 & 0,68 \\
\hline Corsi d'acqua con vegetazione ripariale & 181 & 4,42 & 4 & 0,68 \\
\hline Giardini e parchi & 1031 & 4,42 & 4 & 0,68 \\
\hline Aree con moderate pendenze & 102 & 4,33 & 4 & 0,64 \\
\hline Fascia boscata & 19 & 4,25 & 4 & 0,59 \\
\hline Vigneti inerbiti misti & 1732 & 4,25 & 4 & 0,59 \\
\hline Edificazione di valore architettonico & 1023 & 4,21 & 4 & 0,56 \\
\hline Siepi & 21 & 4,17 & 4 & 0,54 \\
\hline Strada di campagna & 911 & 4,17 & 4 & 0,54 \\
\hline Edificato rurale & 1051 & 4,08 & 4 & 0,49 \\
\hline Edificazione residenziale bassa con verde & 1021 & 3,96 & 4 & 0,42 \\
\hline Prato con copertura omogenea & 112 & 3,83 & 4 & 0,35 \\
\hline Seminativo arborato & 161 & 3,83 & 4 & 0,35 \\
\hline Vialetti & 915 & 3,42 & 3 & 0,11 \\
\hline Corsi d'acqua senza vegetazione arborea & 182 & 3,38 & 3,5 & 0,08 \\
\hline Edificato rurale senza manutenzione & 1052 & 3,38 & 3,5 & 0,08 \\
\hline Seminativo arato & 164 & 3,21 & 3 & $-0,01$ \\
\hline Suolo nudo/Roccia affiorante & 121 & 3,21 & 3 & $-0,01$ \\
\hline Incolto cespugliato e/o con alberi & 131 & 3,08 & 3 & $-0,09$ \\
\hline Vigneto inerbito a rittochino & 1734 & 3,08 & 3 & $-0,09$ \\
\hline Aree monocolturali di grandi dimensioni & 100 & 3,04 & 3,5 & $-0,11$ \\
\hline Prato con copertura non omogenea & 111 & 3 & 3 & $-0,13$ \\
\hline Aree verdi ad uso agricolo & 1033 & 2,96 & 3 & $-0,16$ \\
\hline Vigneto non inerbito a traverso & 1743 & 2,83 & 3 & $-0,23$ \\
\hline Strada asfaltata & 913 & 2,75 & 3 & $-0,28$ \\
\hline Aree pianeggianti o con deboli pendenze & 103 & 2,71 & 2,5 & $-0,30$ \\
\hline Impianti sportivi & 1034 & 2,71 & 3 & $-0,30$ \\
\hline Canali artificiali & 185 & 2,42 & 3 & $-0,47$ \\
\hline Nuovi impianti di vigneto & 1736 & 2,17 & 2 & $-0,62$ \\
\hline Piazzali e parcheggi & 1025 & 2,13 & 2 & $-0,64$ \\
\hline Strada ad alto traffico & 914 & 2,08 & 2,5 & $-0,66$ \\
\hline Vigneto non inerbito a rittochino & 1744 & 1,71 & 2 & $-0,88$ \\
\hline Serre & 171 & 1,29 & 1 & $-1,12$ \\
\hline Sbancamenti in atto & 1735 & 1,21 & 1 & $-1,17$ \\
\hline Edificato industriale-artigianale & 1041 & 1,08 & 1 & $-1,24$ \\
\hline Deposito materiali inerti & 133 & 0,25 & 0 & $-1,72$ \\
\hline
\end{tabular}


poteva generare confusione. Allo stesso modo, per non generare difficoltà di giudizio, la dimensione non è stata distinta ponendo un limite preciso: sopra 0 sotto un determinato valore in ettari. Successivamente, nell'applicazione GIS, si è attribuito la qualità "piccole dimensioni" a tutte le superfici monocolturali di estensione $<5$ ha. La qualità "grandi dimensioni" è stata invece attribuita alle superfici monocolturali $>5$ ha. Anche riguardo alla pendenza le tre classi qualitative: debole, moderata e accentuata non sono state identificate attraverso valori percentuali di acclività. Ciò al fine di non creare dubbi interpretativi al panel di esperti e soprattutto per cogliere l'impressione che ciascun osservatore ha del territorio, basata sulla qualità della pendenza (debole, moderata e accentuata), piuttosto che sulla quantità (valori percentuali). Per ciascun elemento del paesaggio, è stata determinata la media e la mediana dei voti ottenuti. La media è stata poi standardizzata, come indicato da Daniel e Roster (1976) nella definizione del noto Scenic Beauty Estimation method (SBE) del quale il metodo tassonomico quantitativo è una derivazione.

La standardizzazione è necessaria per ovviare al problema che sorge quando i valutatori adottano differenti strategie per assegnare i valori. Alcuni tendono a non usare mai i valori estremi della scala di valutazione, altri invece usano solo gli estremi (bellissimo o bruttissimo) senza usare i valori intermedi. Il metodo più usato per risolvere questo problema consiste nel trasformare i valori attribuiti da ciascun valutatore in punteggi standardizzati attraverso la formula:

$$
z_{i j}=\frac{R_{i j-} \bar{R}_{j}}{s_{j}}
$$

Dove $\mathrm{z}_{i j}=$ punteggio standardizzato, relativo all'elemento del paesaggio iesimo , dato dall'esperto $j$;

$\bar{R}_{i j}=$ media di tutti i punteggi attribuiti ai differenti elementi del pesaggio dall'esperto $j$;

$S j=$ deviazione standard di tutti i punteggi forniti dall'esperto $j$, relativi ai differenti elementi del paesaggio.

La trasformazione z produce una scala con un'origine equivalente

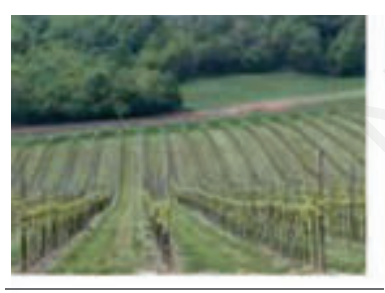

Figura 2. Vigneti a rittochino.

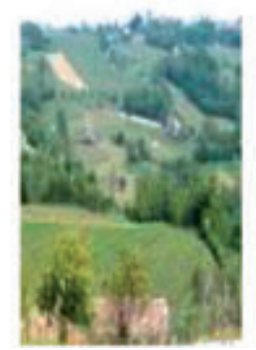

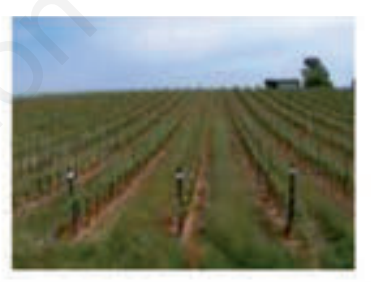

Figura 3. Vigneti a rittochino.

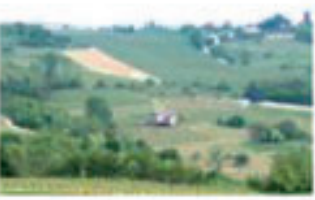

alla media dei punteggi dell'osservatore (ad es: il punteggio medio $\bar{R}_{i j}$ risulta pari a zero sulla scala del punteggio standardizzato).

Inoltre tutti i valori sulla scala $z$ sono espressi in unità uguali alla deviazione standard dei punteggi forniti dall'esperto. Se, ad esempio, la deviazione standard di tutti i punteggi forniti dall'esperto $j$, relativi ai differenti elementi del paesaggio fosse 3 , la media fosse 4 , ed il voto per un determinato elemento del paesaggio fosse 1, la differenza di 3 punti $(4-1=3)$, rispetto alla media, diventa una differenza pari a 1 sulla scala $z$ standardizzata). La standardizzazione consente, non solo di eliminare le differenze arbitrarie fra gli esperti su come utilizzano la scala del punteggio, ma anche di eliminare le differenze causate da differenti scale. Ad esempio, nel presente caso di studio si è utilizzata una scala da 0 a 6 ma si sarebbe potuto utilizzare un range di valori più grande 0 più piccolo. Operando la standardizzazione le differenti scale diventavano paragonabili.

Nella Tabella 1 si riportano i valori della media, della mediana e della media standardizzata dei punteggi, espressi dal panel di esperti per i singoli elementi del paesaggio.

Si descrive sinteticamente la metodologia seguita per l'elaborazione dei dati utilizzando il GIS in ambiente ESRI ArcGis 10.1.

Lo strato vettoriale di uso del suolo è stato intersecato con lo strato delle pendenze, ottenendo per ciascun poligono il valore medio di pendenza. I valori di pendenza sono stati divisi in 3 classi:

1 = pendenza bassa $0-10^{\circ}$ (indicata in modo qualitativo al panel come "aree pianeggianti o con deboli pendenze");

2 = pendenza media $10-20^{\circ}$ (indicata come "aree con pendenze moderate");

3 = pendenza alta $>20^{\circ}$ (indicate nella scheda come aree con pendenze accentuate).

Per ciascun poligono si è quindi assegnato il valore del voto del panel in relazione alla classe di pendenza. Ad esempio, se la pendenza media del poligono è 15\% esso ricade nella classe: "pendenza moderata" ed il valore attribuito, secondo la Tabella 1, è 4,33 (che standardizzato diventa 0,1995$)$. Come precedentemente detto, i poligoni relativi ai diversi usi del suolo sono stati classificati in base alle dimensione. Alle superfici $<5$ ha è stato assegnato il voto medio del panel attribuito agli appezzamenti di piccole dimensioni; mentre alle superfici $>5$ ha è stato assegnato il voto medio del panel per i gli appezzamenti monocolturali di grandi dimensioni. In ArcMap, attraverso il comando join, la tabella

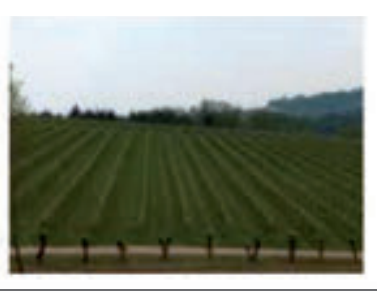

Figura 4. Vigneti a rittochino.

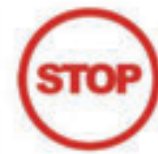

Figura 5. Pausa per il voto.
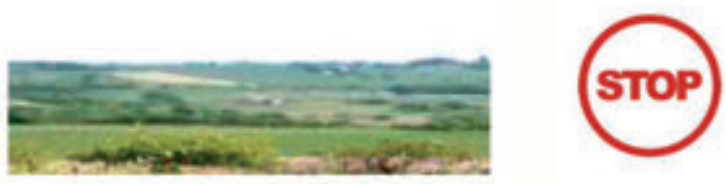

Figura 6. Pendenza accentuata. Figura 7. Pendenza moderata. 
del database del panel è stata collegata allo shp-file dell'uso del suolo sopradescritto. In questo modo, per ogni poligono, sono stati assegnati i punteggi corrispondenti: 1 ) alla somma dei 3 voti medi relativi al valore paesaggistico assegnati all'uso del suolo, alla dimensione e alla pen-



Figura 10. Scheda di votazione consegnata a ciascun esperto del panel. In basso, evidenziate in azzurro, sono riportate le tipologie di paesaggio che si riferiscono alla componente morfologica dell'analisi Tassonomica quantitativa. denza (secondo la metodologia indicata da Barocchi); e 2) somma dei tre voti standardizzati. Il range dei punteggi, per i due metodi, è risultato il seguente: 1) metodo Barocchi originale, da 6,96 a 13,25; 2) metodo Barocchi con standardizzazione, da $-1,58$ a 2,87.

Al fine di rendere paragonabili le legende delle Figure 11 e 12, i valori di separazione delle impressioni negative (colori nella gamma del rosso) da quelle positive (azzurri) sono risultati il seguenti: a) metodo Barocchi originale, valore di separazione bello/brutto $=9$; b) metodo Barocchi con standardizzazione; valore di separazione bello/brutto $=0$. Si sono così prodotte due carte del valore paesaggistico dell'area in esame.

\section{Analisi Tassonomica Quantitativa del Paesaggio, rappresentata dinamicamente secondo la metodologia per buffer}

La rappresentazione geografica del valore paesaggistico, effettuato attribuendo alle singole unità di paesaggio il valore derivante dall'analisi tassonomica quantitativa, non consente di rappresentarne la percezione dinamica.

Nello svolgimento del presente studio si è messa a punto una nuova metodologia di rappresentazione dei risultati dell'analisi tassonomica qualitativa, più vicina al modo naturale di valutazione dinamica del paesaggio. Le carte prodotte consentono sia di confrontare in modo quantitativo il valore del paesaggio a distanza di anni sia di valutare l'influenza che i singoli elementi del paesaggio, o gli interventi attuati nel territorio, hanno sulla percezione in un determinato intorno.

Come è noto, la percezione dinamica rappresenta oggi la principale modalità di osservazione del paesaggio e rappresenta uno degli strumenti più idonei nelle operazioni di rilievo paesistico. La percezione dinamica può essere ottenuta negli gli spostamenti in aereo, elicottero, deltaplano, ecc.; mentre la percezione dinamica a livello del suolo, tramite gli spostamenti su strada e fuoristrada, a piedi o con mezzi di locomozione, è senza dubbio quella più importante per l'apprezzamento del valore del "paesaggio del vino" e quindi per gli aspetti relativi al valore delle produzioni agricole di qualità legate a territori specifici. Nel caso si voglia valutare la percezione da parte di un viaggiatore in auto, occorre individuare quali siano le parti del territorio che in maniera più forte si presentano alla vista di chi percorre una strada.

Questa impostazione "automobilistica" è però limitante quando si tratta dei territori del vino nei quali, richiamando la carta, "il paesag-

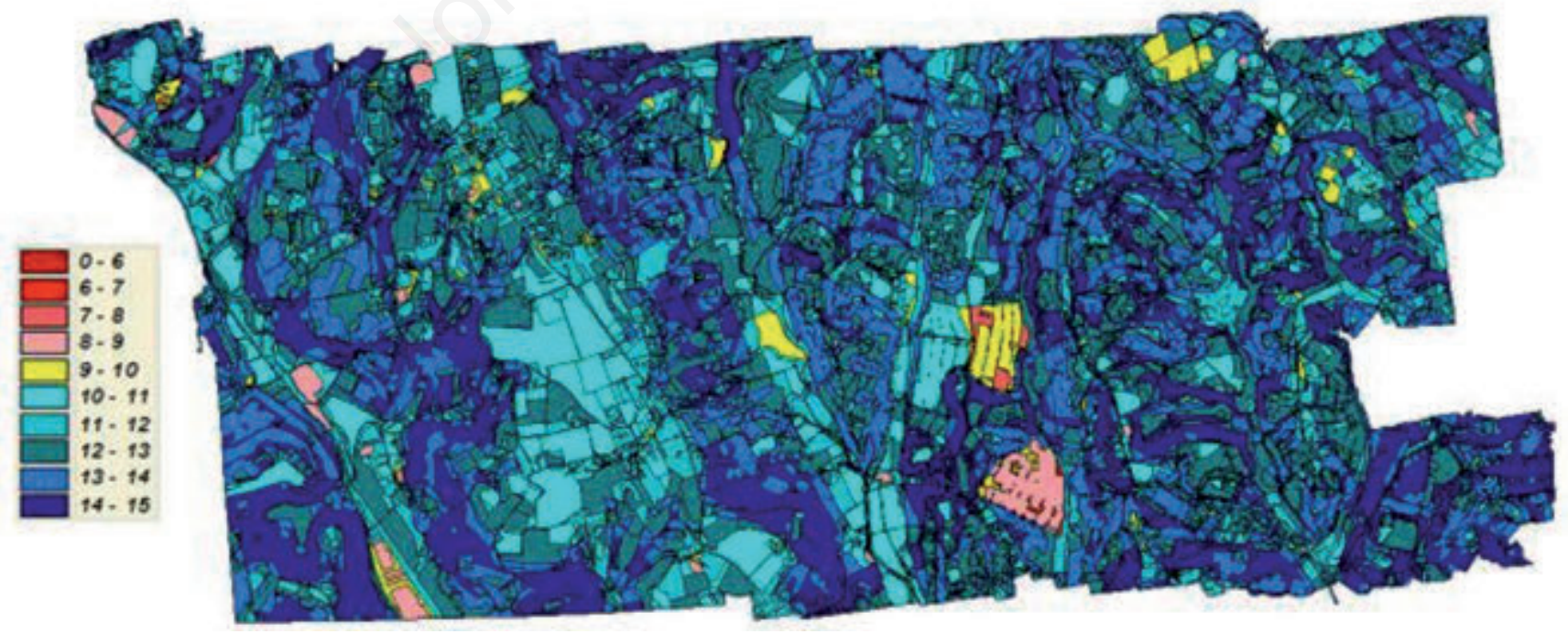

Figura 11. Analisi Tassonomica Qualitativa del paesaggio. Somma dei voti relativi al valore paesaggistico dell'uso del suolo, dell' acclività e delle dimensioni delle superfici monocolturali. 
gio è un bisogno sociale in relazione all' aumento di disponibilità di tempo libero e del bisogno di cultura". In questi territori il paesaggio viene fruito nei momenti di relax, quindi non solo in auto ma anche a piedi; pertanto risulta difficile stabilire percorsi preferenziali e, di conseguenza, l'immagine paesaggistica di quei percorsi.

La metodologia messa a punto nel presente lavoro non utilizza percorsi preferenziali, ma simula l'osservazione del territorio su una fitta griglia di punti panoramici equidistanti. In altre parole, è come se un numero elevatissimo di osservatori, dotati di una sensibilità paesaggistica esattamente uguale, giudicassero contemporaneamente il paesaggio su una fitta griglia di posizioni equidistanti 50 metri. A ciascun punto della griglia viene assegnato il valore medio ponderato derivante dall'analisi tassonomica qualitativa su una estensione di territorio pari ad un buffer circolare di $200 \mathrm{~m}$ di raggio. Per questo motivo la metodologia è stata definita: Analisi Tassonomica Quantitativa per Buffer (ATQB).

L'interpolazione dell'indice ATQB consente di produrre una mappa distribuita della Valutazione del Paesaggio che, in qualche misura, contiene elementi riconducibili ad una Percezione Visiva Dinamica. Per ciascun punto, il quadro paesaggistico ha una apertura visiva di $360^{\circ}$ ed una profondità di veduta laterale breve, pari a $200 \mathrm{~m}$, in modo da premiare i dettagli e minimizzare l'influenza degli ostacoli sull'estensione di superficie di territorio osservabile. La metodologia attribuisce valori mediati di paesaggio a superfici circolari fortemente sovrapposte e si basa, anche se in modo approssimativo, sui principi gestaltistici dell'unificazione percettiva proposti da Metzger (1984); secondo i quali gli esseri umani organizzano e raggruppano insiemi di stimoli isolati sulla base di alcuni fattori, fra cui: 1) la vicinanza, considerando una totalità unitaria gli elementi vicini; 2) la somiglianza, unificano gli elementi simili; 3) la continuità, unificando gli elementi che tendono alla continuità anche se non sono uniti.

La metodologia di sviluppo dell'analisi in ambiente GIS è relativamente semplice e si compone delle seguenti fasi: 1) creazione di uno shp file di punti di griglia, spaziati tra di loro di $50 \mathrm{~m}$; 2) produzione di un buffer di questi punti, con raggio di 200 metri ciascuno (Figura 13); 3) trasformazione in GRD (celle di 1 metro) dello shp file del valore paesaggistico, ricavato applicando l'analisi tassonomica qualitativa; 4) utilizzo del comando Zonal Statistics per la produzione di una tabella con i valori statistici per ciascun cerchio; 5) Utilizzazione del comando join per collegare il valore paesaggistico ATQB (valore della media) con lo shp file dei cerchi; 6) trasformazione dei cerchi in centroidi lasciando la tabella inalterata; 7) Generazione del TIN, utilizzando i centroidi creati; 8) interpolazione della griglia di punti, con produzione della mappa a curve di livello dell "Indice della Percezione Visiva Dinamica" ATQB.

La Figura 14 mostra un particolare della griglia con un punto di osservazione. Le Figure 15 e 16 mostrano rispettivamente la mappa della distribuzione per buffer dell'indice ATQB e dell'indice ATQB standardizzato. Dalla notevole somiglianza delle due mappe si evince che il panel di esperti è stato formato da valutatori in grado di esprimere giudizi equilibrati e capaci di utilizzare tutta la scala di punteggio disponibile. Nella Figura 17 l'indice ATQB standardizzato è stato sovrapposto al fotomosaico aereo. Le Figure 18 e 19 mostrano rispettivamente la visualizzazione tridimensionale di un'area ove sono presenti sbancamenti in atto e la sovrapposizione 3D dell'indice ATQB.

\section{Considerazioni sui risultati forniti dall'analisi del pae- saggio e suggerimenti}

È importante sottolineare che la valutazione tassonomica quantitativa del paesaggio non è in grado da sola di esaurire il tema assai complesso della valutazione percettiva del paesaggio del vino. Come detto in premessa, essa fornisce uno strumento geografico della rappresentazione del valore paesaggistico che, insieme ad altre opportune analisi, è in grado di fornire indicazioni utili per il governo del territorio.Un fattore di pregio dell'analisi tassonomica quantitativa, così come è stata implementata nel presente studio, è l'aver utilizzato un panel di esperti locali. Questo modo di operare consente a qualsiasi analista del paesaggio, anche se estraneo al territorio da analizzare, di operare su territori ove non ha sviluppato una sufficiente "familiarizzazione" percettiva (Barrocchi, Sito Web 2005-2008). Il panel di esperti locali fa si che il giudizio sul paesaggio sia demandato a coloro che ne fruiscono e che ne dovranno tener cura, senza influenze e condizionamenti esterni.

I limiti del presente studio non hanno consentito l'estensione del panel a tipologie diverse di fruitori del paesaggio, quali i turisti di varie provenienze ed in genere, ad una più ampia platea di stakeolders, ovvero di portatori di interessi non solo economici ma anche culturali, legati al tempo libero e al paesaggio del vino. Si forniscono alcune indica-

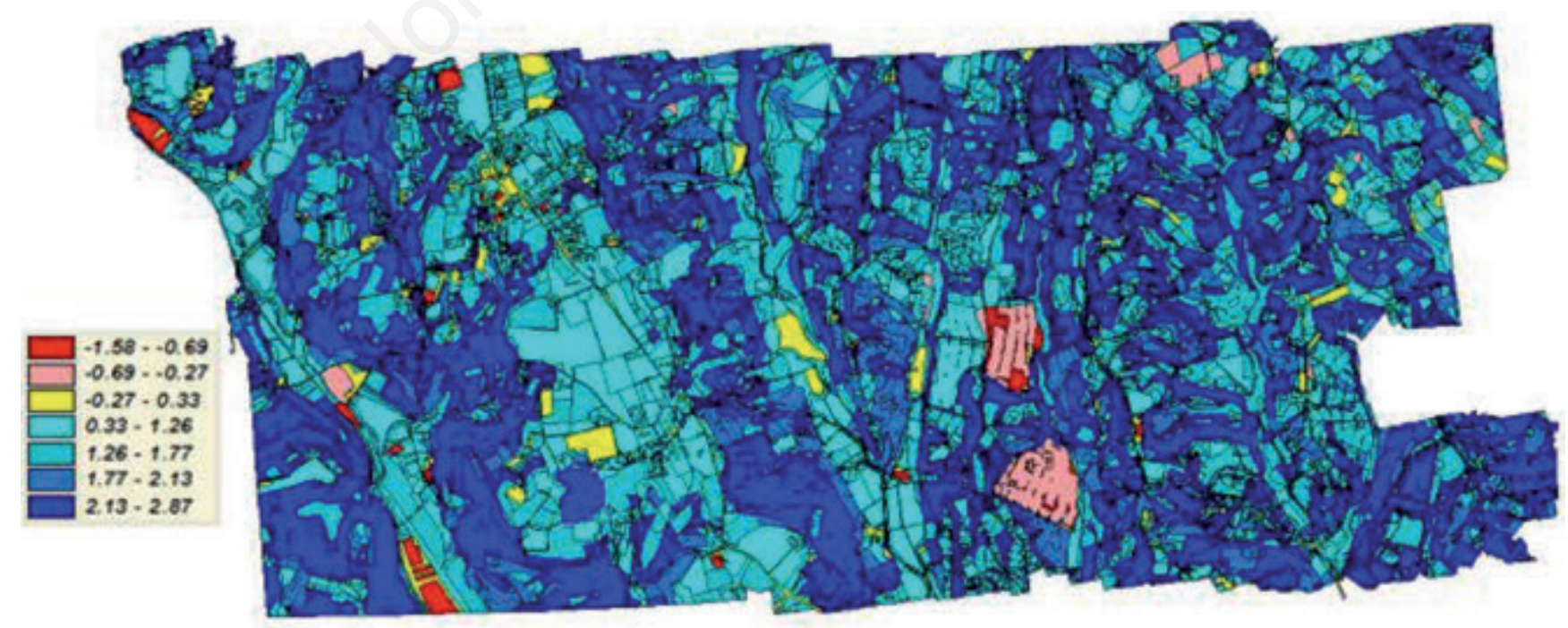

Figura 12. Analisi Tassonomica qualitativa del paesaggio. Somma dei voti standardizzati relativi al valore paesaggistico dell'uso del suolo, dell'acclività e delle dimensioni delle superfici monocolturali. 
zioni, utili alla valorizzazione del paesaggio da parte delle Pubbliche Amministrazioni e degli agricoltori attenti a proprio territorio, che emergono dai punteggi assegnati dal panel nella valutazione degli elementi del paesaggio dell'area di studio di Conegliano (Tabella 1). Riguardo all'uso viticolo del territorio si può osservate come il "vigneto storico" (Figura 20) sia la tipologia maggiormente apprezzata. Seguono, in ordine decrescente di apprezzamento: il vigneto in traverso inerbito; i vigneti inerbiti misti (ovvero, quella tipologia di paesaggio percepita in modo unitario come un fitto intreccio di piccoli vigneti in traverso e a rittochino inerbiti). A questi seguono, in ordine crescente di giudizio negativo: i vigneti a rittochino inerbiti, i vigneti in traverso non inerbiti, ed infine i vigneti a rittochino non inerbiti. Sempre riguardo ai vigneti, sono percepiti come gradevoli quelli di piccole dimensioni, e sgradevoli quelli di grandi dimensioni. Il paesaggio più apprezzato è quello su pendenze elevate. Anche le pendenze moderate sono apprezzate, seppure in modo meno evidente. Le aree pianeggianti ottengono invece un giudizio moderatamente negativo.Il bosco compat- to è molto gradito, ed in misura inferiore sono gradite le fasce boscate. Inatteso è stato il giudizio estetico molto positivo attribuito agli oliveti. Si tratta di una tipologia di uso del suolo molto rara nell'area in esame, ma ben conosciuta ed apprezzata in Italia. Forse la rarità e la capacità di evocare una "familiarità" (nel significato attribuito da Barocchi a questo termine) rendono questo uso del suolo significativamente apprezzato.

Fra gli elementi naturali/seminaturali i corsi d'acqua appartenenti al reticolo idrografico provvisti di vegetazione ripariale sono risultati molto graditi, mentre quelli sprovvisti di vegetazione di ripa risultano apprezzati in modo molto modesto. In questo caso, l'elemento di piacevolezza determinato dalla presenza di acqua sovrasta la negatività dovuta all'assenza di vegetazione ripariale. I canali artificiali, diversamente dai corsi d'acqua appartenenti al reticolo idrografico, hanno ottenuto un giudizio negativo. Le siepi sono considerate piacevoli, ma in misura moderata, come pure i prati e i seminativi arborati. Le aree recentemente sbancate per l'impianto/reimpianto di vigneti, con suolo

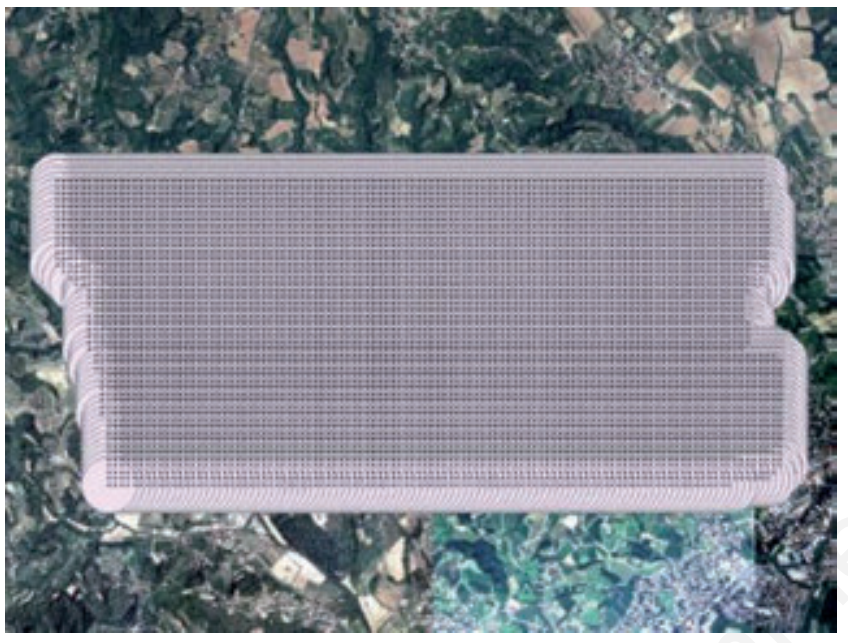

Figura 13. Rappresentazione della griglia di punti e dei buffer utilizzati nell'analisi ATQB.

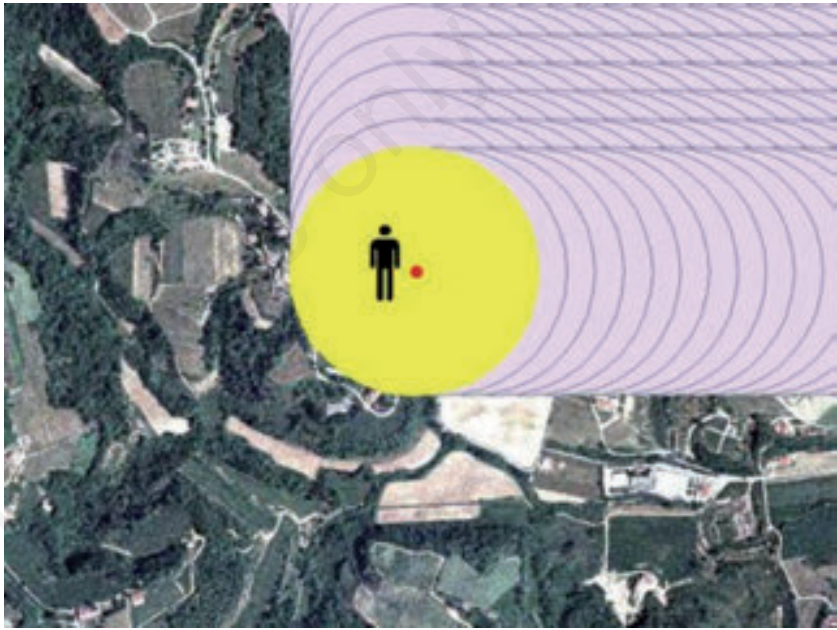

Figura 14. Particolare di un punto di osservazione dell'analisi Analisi Tassonomica Quantitativa applicata secondo la metodologia per buffer (ATQB).

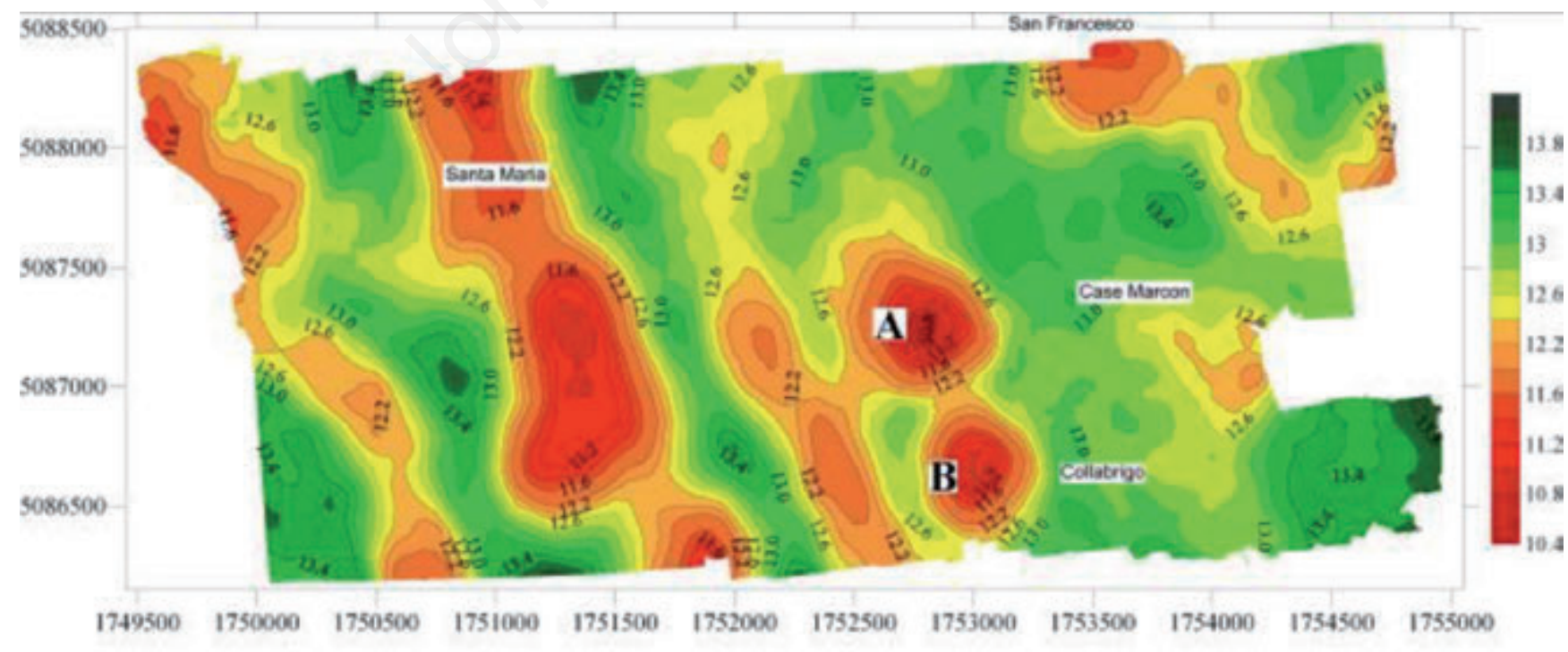

Figura 15. Mappa della Valutazione del Paesaggio (Percezione Visiva Dinamica). Distribuzone dell'Indice Paesaggistico derivante dall' Analisi Tassonomica Quantitativa applicata secondo la metodologia per buffer (ATQB). Coordinate WGS84 UTM32N. 


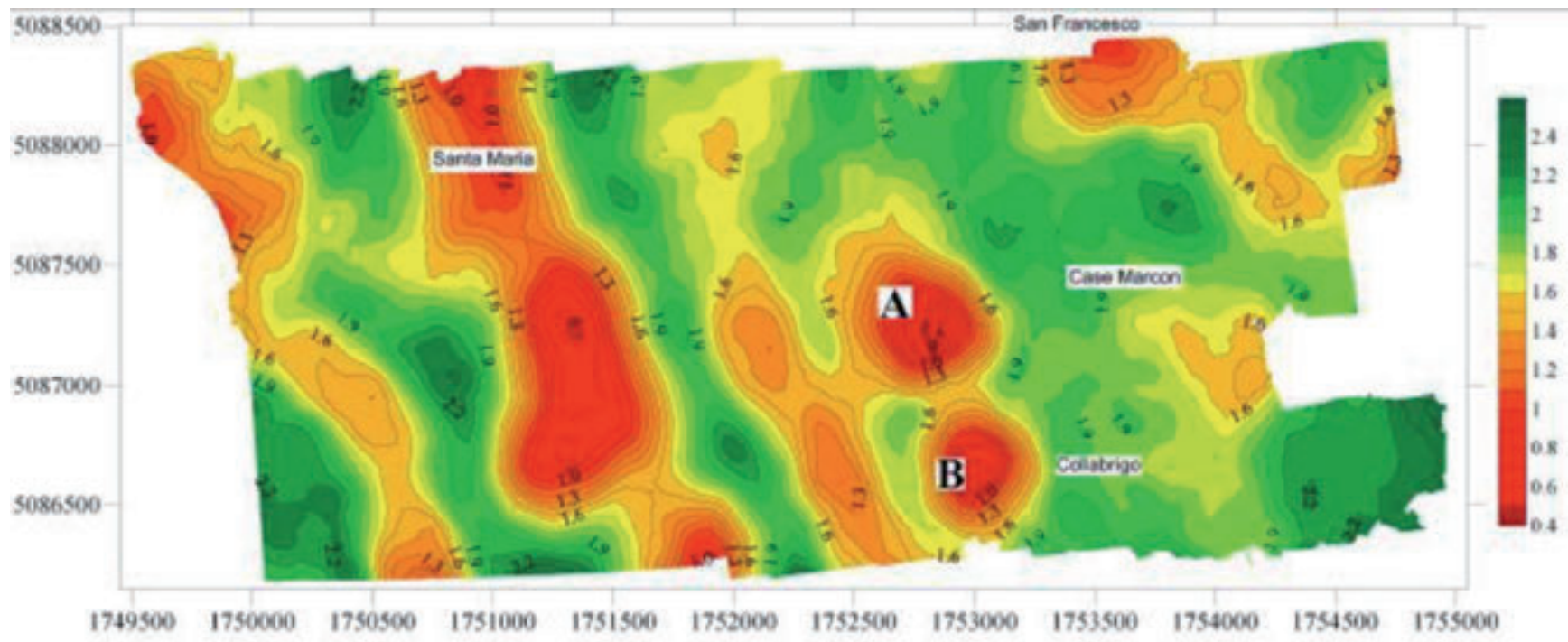

Figura 16. Mappa della Valutazione del Paesaggio (Percezione Visiva Dinamica). Distribuzione dell'Indice Paesaggistico standardizzato derivante dall' Analisi Tassonomica Quantitativa, applicata secondo la metodologia per buffer (ATQB). Coordinate WGS84 UTM32N.

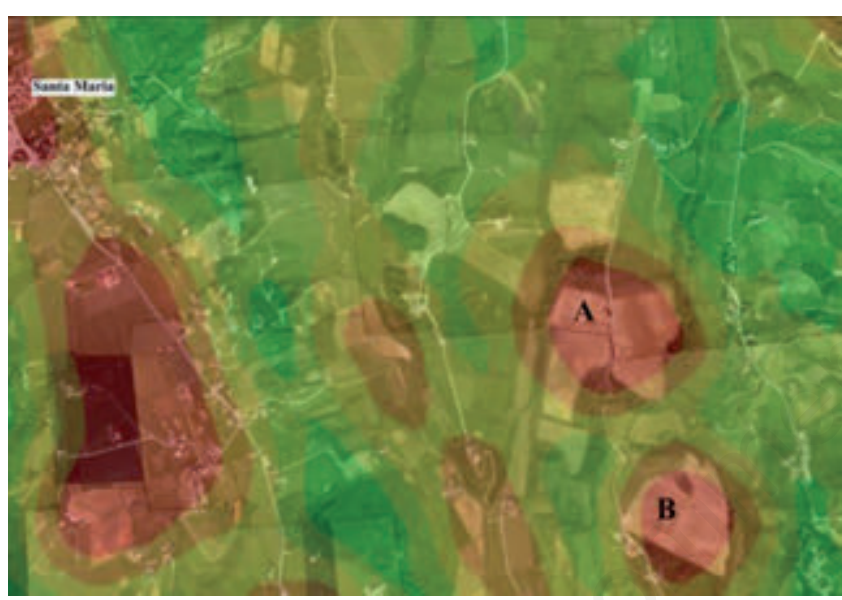

Figura 17. Sovrapposizione su fotomosaico aereo dell'Indice Paesaggistico standardizzato derivante dall' Analisi Tassonomica Quantitativa per buffer (ATQB).

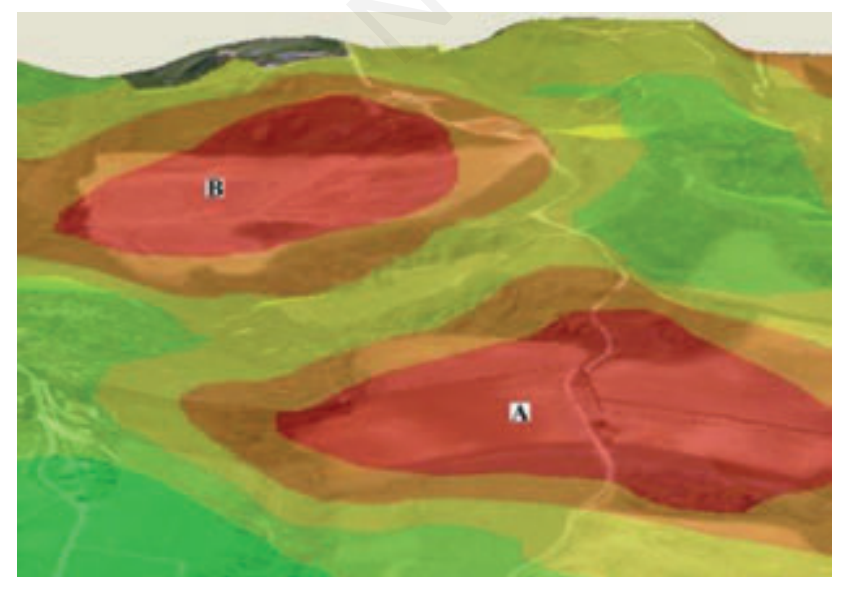

Figura 19. Visualizzazione tridimensionale della zona A e B della Figura 17, con sovrapposizione dell' Indice Paesaggistico standardizzato derivante dall' Analisi Tassonomica Quantitativa per buffer (ATQB).

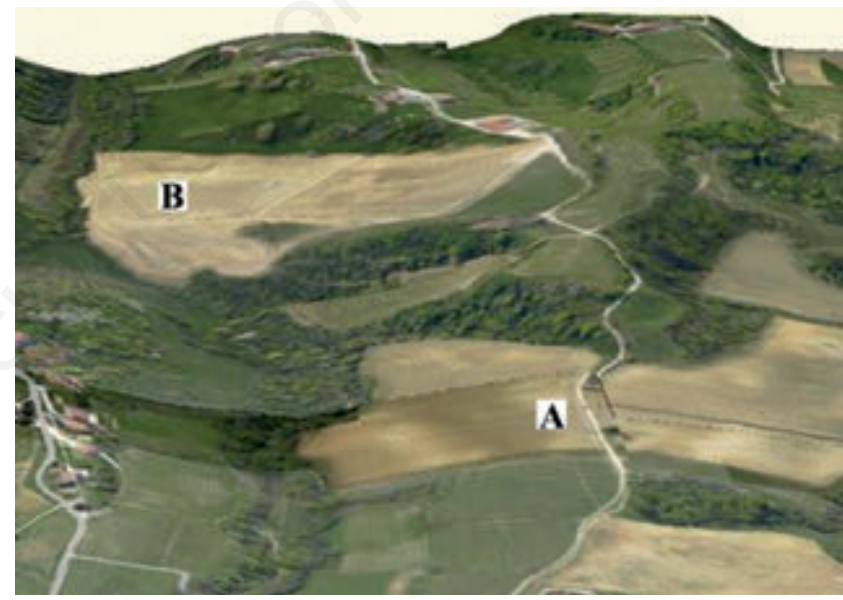

Figura 18. Visualizzazione 3D della zona A e B della Figura 17.

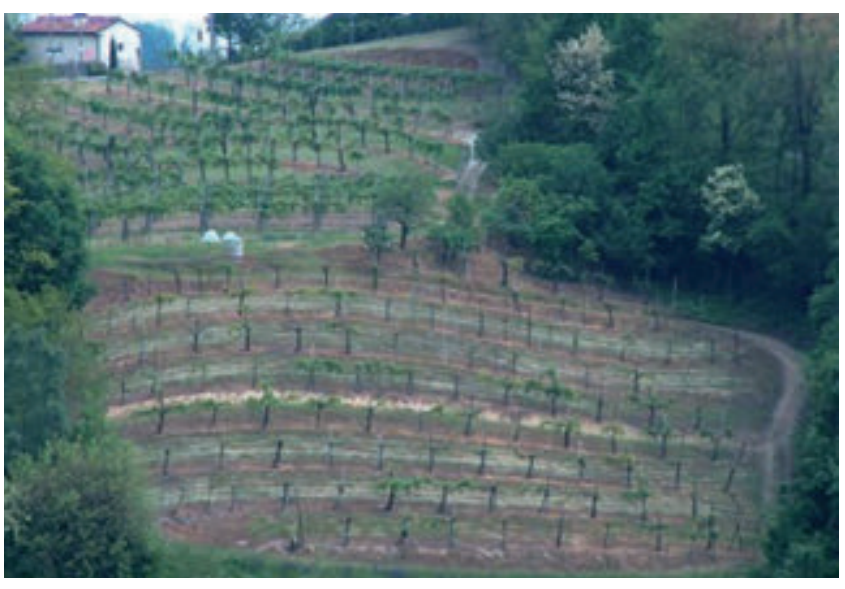

Figura 20. Vigneto storico. 
nudo in vista, sono percepite in modo estremamente negativo. In genere, i vigneti in fase di impianto, anche se su superfici non sbancate, sono percepiti negativamente. L'edificato di valore storico, soprattutto se in vicinanza di elementi rurali, è stato considerato molto attraente.

\section{Analisi dell'eterogeneità del paesaggio}

Nell'ecologia del paesaggio è molto importante lo studio dell'eterogeneità superficiale, per le sue conseguenze sulla biodiversità. Una delle principali minacce alla biodiversità biologica è la frammentazione di origine antropica degli ambienti naturali (Henle et al., 2004). Essa determina la riduzione in superficie degli ambienti naturali e l'aumento dell'isolamento, influenzando la struttura e la dinamica di determinate popolazioni e specie animali e vegetali sensibili, fino ad alterare i parametri di comunità, le funzioni ecosistemiche e i processi ecologici.

Per l'area di studio nell'area di Conegliano si sono scelti indici appropriati (Tabella 2) a rappresentare i concetti di base della quantificazione dei pattern del landscape, come definiti da McGarigal and Mark (1995). Nell'applicazione GIS si è proceduto nel seguente modo: 1) si è convertito lo shp file dell'uso del suolo in GRD (con cella 2 metri); 2) tramite l'estensione Patch Analyst si è creata una maglia di esagoni (regioni) di 5 ha ciascuno; 3) si è lanciata l'estensione PatchGrid (Analisi per regioni), ottenendo per ciascun esagono i valori degli indici della indicati nella Tabella 2 ; 4 ) si è poi proceduto all'interpolazione dei valori in ambiente Surfer 8.0 per ottenere le Figure 21, 22 e 23.

Si riportano le formule relative agli indici calcolati su ciascun esagono, come segue:

$$
N P=\sum N_{p}
$$

Dove $N_{p}=$ numero di Patches.

$$
M P S=\frac{\sum_{j=1}^{n} A_{j}}{n_{p}}
$$

Dove $A_{j}=$ Area (ha) dell 'j-esimo Patch e $n_{p}$ è il numero di Patches.

$$
T E=\sum_{j=1}^{n} \operatorname{Per}_{j}
$$

Dove $P e r_{j}=$ Perimetro (m) dell' j-esimo Patch, $n=$ numero di Patches.

$$
E D=\frac{\sum_{j=1}^{n} \operatorname{Per}_{j}}{T_{h a}}
$$

Dove $\operatorname{Per}_{j}=$ Perimetro (m) del $j$-esimo Patch e $T_{h a}=$ area dell'esagono (ha).

$$
M S I=\frac{\sum_{j=1}^{n} \frac{0,25 \mathrm{Per}_{j}}{\sqrt{A_{j}}}}{N_{p}}
$$

\begin{tabular}{|c|c|c|c|c|}
\hline Concetto & Indice & Codice & Dimensione & Significato \\
\hline Patchness & $\begin{array}{l}\text { Numero di patch } \\
\text { Dimensione media dei patch }\end{array}$ & $\begin{array}{l}\text { NP } \\
\text { hPS }\end{array}$ & $\begin{array}{l}\text { Numero } \\
\text { Ha }\end{array}$ & $\begin{array}{l}\text { Indice semplice che misura la frammentazione del paesaggio } \\
\text { Indice da leggere insieme al valore di NP. MPS fornisce la dimensione media dei patch }\end{array}$ \\
\hline Margine & $\begin{array}{l}\text { Densità totale } \\
\text { Densità dei margini }\end{array}$ & $\begin{array}{l}\text { TE } \\
\text { ED }\end{array}$ & $\begin{array}{c}M \\
M / h a\end{array}$ & $\begin{array}{l}\text { Indica la lunghezza totale dei margini su un'area } \\
\text { Indica la densità dei margini per unità di superficie }\end{array}$ \\
\hline \multirow[t]{3}{*}{ Forma } & Indice di forma media & MSI & Rapporto & $\begin{array}{l}\text { La formula misura la complessità della forma. L'indice assume valore } 1 \text { quando } \\
\text { la macchia è circolare (dati vettoriali) oppure quadrata (dati raster) } \\
\text { e aumenta senza limite all'aumento dell'irregolarità del perimetro. }\end{array}$ \\
\hline & $\begin{array}{l}\text { Dimensione media } \\
\text { frattale dei patch }\end{array}$ & MPFD & Rapporto & $\begin{array}{l}\text { È un indice utilizzato per valutare la complessità della forma. Assume valore } 1 \text { quando i } \\
\text { patch sono circolari (dati vettoriali) o quadrata (dati raster) a bassa complessità; } \\
\text { mentre si avvicina al valore } 2 \text { all'aumento della complessità del perimetro }\end{array}$ \\
\hline & $\begin{array}{l}\text { Dimensione media } \\
\text { frattale dei patch, } \\
\text { pesata sull'area }\end{array}$ & AWMPFD & Rapporto & $\begin{array}{l}\text { Ha il medesimo significato di MPFD, con l'aggiunta, ad ogni patch, della ponderazione } \\
\text { per l'area del patch }\end{array}$ \\
\hline \multirow[t]{2}{*}{ Eterogeneità } & $\begin{array}{l}\text { Indice di diversità } \\
\text { di Shannon }\end{array}$ & SDI & Rapporto & $\begin{array}{l}\text { Lo SDI misura la diversità dei patch costitutivi del paesaggio. L'indice di Shannon, può } \\
\text { variare tra zero e l'infinito, aumenta al crescere del numero dei tipi di patch e/o } \\
\text { quando la distribuzione dell'area tra i tipi di patch è più equilibrata }\end{array}$ \\
\hline & $\begin{array}{l}\text { Indice di eterogeneità } \\
\text { di Shannon }\end{array}$ & SEI & Rapporto & $\begin{array}{l}\text { L'indice rileva quanto il paesaggio, a prescindere dal numero di elementi che contiene, } \\
\text { si avvicina al perfetto equilibrio fra le estensioni relative delle diverse tipologie di } \\
\text { patch. Valori dell'indice prossimi a 1, indicano che il paesaggio considerato è formato } \\
\text { da elementi con estensioni relative simili. Bassi valori, prossimi a 0, indicano che il } \\
\text { paesaggio è dominato da elementi con estensioni relative molto diverse }\end{array}$ \\
\hline
\end{tabular}

Dove Per $_{j}=$ Perimetro (m) dell ' $j$-esimo Patch, $A_{j}=$ Area (ha) del $j$ esimo Patch, $N_{p}=$ numero di Patches.

Tabella 2. Indici utilizzati per la quantificazione dei pattern del landscape. 


$$
M P F D=\frac{\sum_{j=1}^{n} \frac{2 \ln (0,25) \mathrm{Per}_{j}}{\ln A_{j}}}{N_{p}}
$$

Dove $P e r_{j}=$ Perimetro (m) del $j$-esimo Patch, $A_{j}=$ Area (ha) del $j$ esimo Patch, $N_{p}=$ numero di Patches.

$$
A W M P F D=\sum_{j=1}^{n} \frac{2 \ln P e r_{j}}{\ln A_{j}} \cdot \frac{A_{j}}{\sum_{j=1}^{n} A_{j}}
$$

Dove $P e r_{j}=$ Perimetro (m) del j-esimo Patch, $A_{j}=$ Area (ha) del $j$ esimo Patch, $N_{p}=$ numero di Patches.

$$
S D I=-\sum_{j=1}^{s} p_{j} \log p_{j}
$$

Dove $p_{j}$ è la proporzione dell'j-esima classe d'uso del suolo e $s$ è il numero delle classi.

$$
S E I=\frac{-\sum_{j=1}^{\infty} p_{j} \log p_{j}}{\log s}
$$

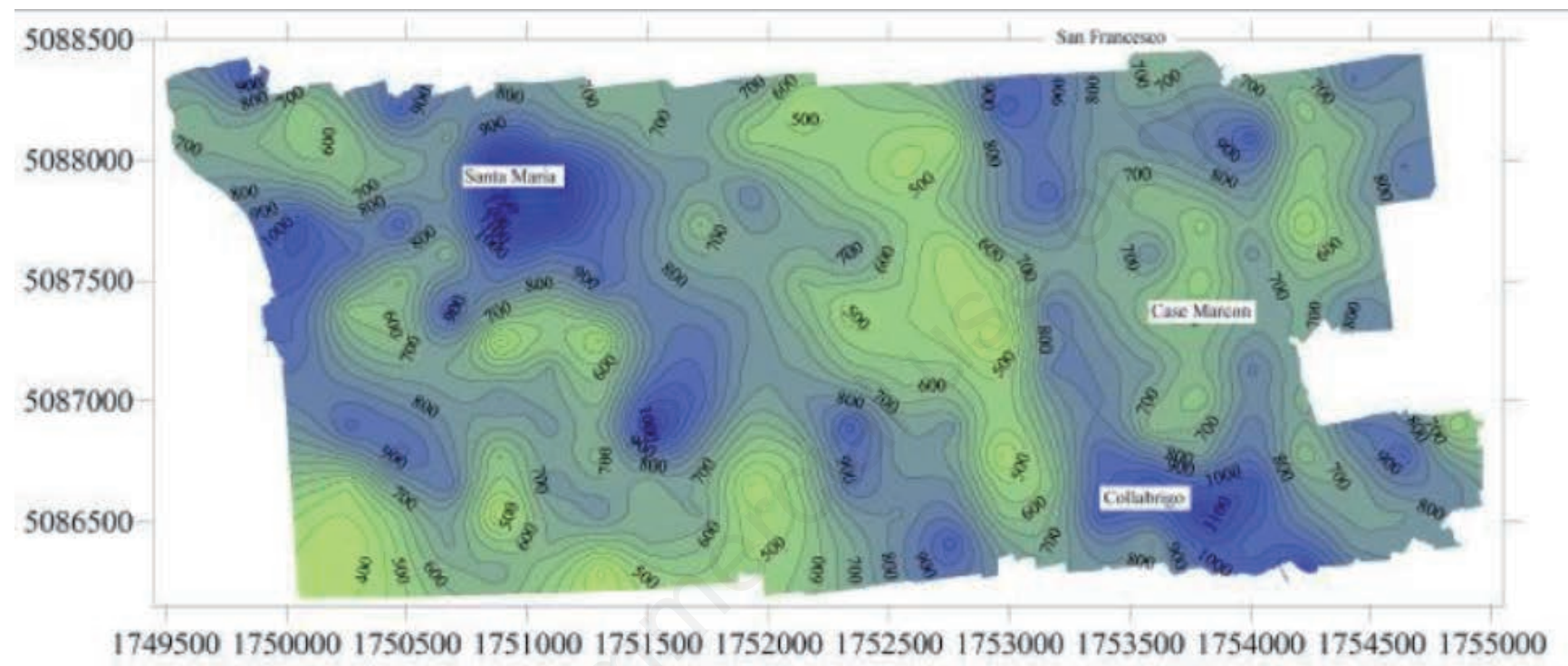

Figura 21. Indice Densità dei margini (ED). I valori piuttosto elevati $(\mathrm{m} / \mathrm{ha})$ di margini indicano una notevole frammentazione del territorio.

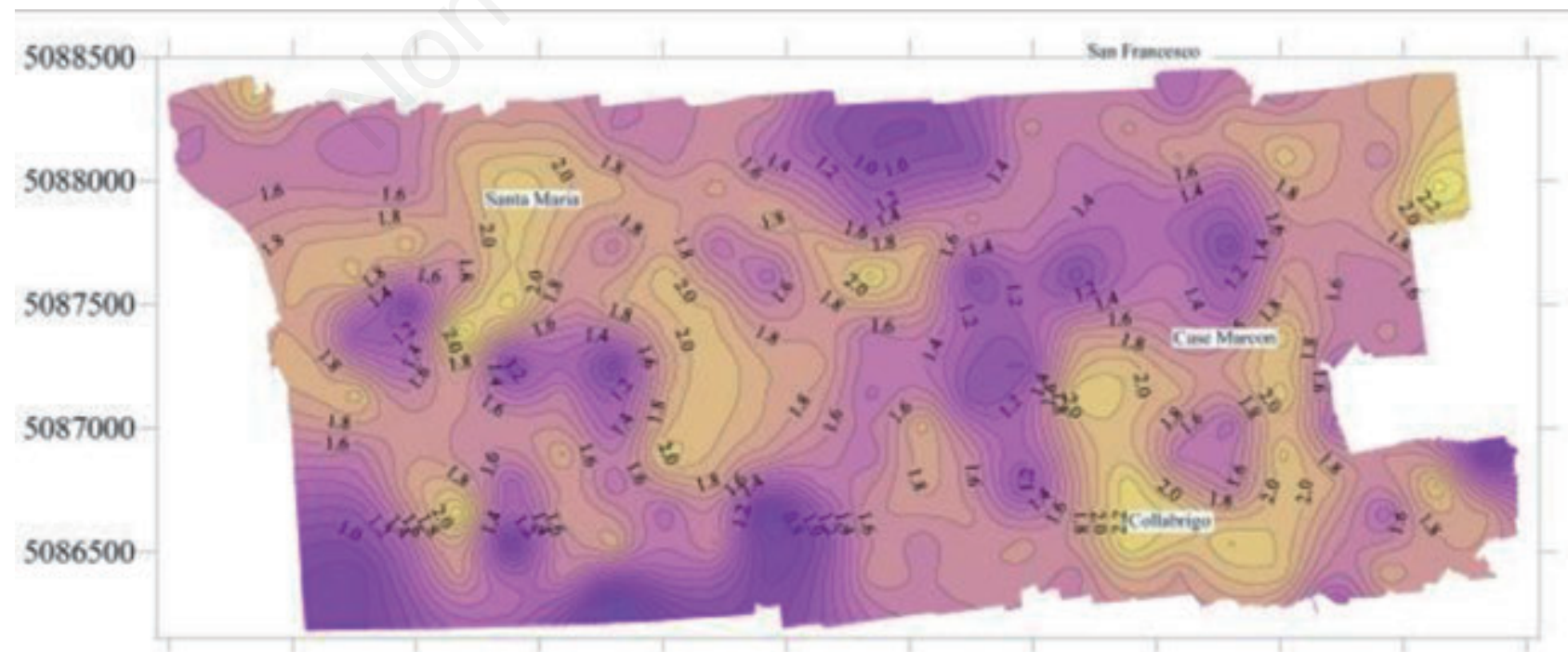

174950017500001750500175100017515001752000175250017530001753500175400017545001755000

Figura 22. Indice di Diversità di Shannon (SDI). I valori piuttosto bassi indicano una bassa diversità nei tipi di patch. 
Dove $p_{j}$ è la proporzione dell'j-esima classe d'uso del suolo e $s$ è il numero delle classi.

L'analisi ha fornito i risultati esposti nella Tabella 3. Le Figure 21, 22 e 23 mostrano le distribuzioni spaziali di alcuni degli indici più significativi derivanti dalla Patch analysis.

\section{Considerazioni sui risultati forniti dalla patch analysis e suggerimenti}

Nell'area di studio nel comune di Conegliano, gli indici (Tabella 3) evidenziano un numero molto elevato di patch, col lunghezza complessiva molto elevata $(682,5 \mathrm{~km})$, con area media piuttosto piccola $(0,26$ ha) ed uno densità di margini ad ettaro molto elevata (740 metri). La forma dei patch non risulta molto complessa, appaiono premiate le forme regolari su quelle irregolari (indice MSI). Inoltre, la dimensione media frattale dei patch evidenzia che sono prevalenti le forme poco complesse, somiglianti a quadrilateri regolari (indici MPFD e AWMPFD). Lindice di diversità di Shannon è risultato abbastanza basso, pari a 1,62, dimostrando che nell'area in esame esiste una bassa diversità nei tipi di patch. L'indice di eterogeneità di Shannon è risultato pari a 0,69 . Questo valore, prossimo a 1 , indica che il paesaggio dell'area di studio è formato da patch con estensioni relative simili fra loro. La frammentazione è senza dubbio un aspetto dominante nel paesaggio dell'area di studio; comunque, riguardo al vigneto, ovvero alla conduzione agricola predominante, non si può sostenere che si debba cercare di ridurla; visto che l'analisi del paesaggio ha premiato i vigneti di piccole dimensioni. Per migliorare le condizioni predisponenti all'aumento della biodiversità si suggerisce la valorizzazione dei margini fra patch diversi, trasformandoli in fasce ecotonali; ovvero in biotopi di transizione tra ecotipi diversi, caratterizzati dal fatto di possedere una maggiore diversità e varietà biologica. Per raggiungere questo obiettivo si dovrebbe incrementare sia la funzione rifugio sia la funzione di corridoio biologico dei margini, favorendo la connettività con le aree aventi funzione di riserva biologica, quali i boschi, le fasce boscate, le fasce cespugliate, i corsi d'acqua con vegetazione ripariale, e l'incolto cespugliato e/o con alberi. I corsi d'acqua senza vegetazione ripariale dovrebbero essere curati attraverso l'attuazione di un piano di rivegetazione appropriato a favorire la biodiversità.

\section{Valutazione dell'impatto dei movimenti di terra attuati in viticoltura nell'area di studio, tramite l'analisi diacronica dei modelli digitali del terreno}

\section{La risorsa suolo}

Prima di trattare il tema dell'impatto degli sbancamenti e dei livellamenti del terreno sull'ambiente è necessario richiamare alcuni concetti fondamentali sul suolo, inteso come risorsa naturale. Ciò consente di inquadrare la problematica in modo adeguato. Una definizione moderna di "suolo" è stata fornita dal Soil Survey Staff degli Stati Uniti (Soil Survey Staff, 1999) secondo il quale: "Il suolo è un corpo naturale formato dai solidi (minerali e materia organica), da liquido e dai gas, che è presente sulla superficie della terra occupando spazio, ed è caratterizzato da uno o da entrambi $i$ seguenti elementi: 1) gli orizzonti, o strati, che sono distinguibili dal materiale iniziale come conseguenza delle aggiunte, perdite, trasferimenti e trasformazioni di energia e materia; 2) la capacità di sostenere piante aventi apparato radicale in un

Tabella 3. Valori osservati degli indici per la quantificazione dei pattern del landscape.

\begin{tabular}{lcc} 
Indice & Codice & Valori \\
& & osservati \\
Area totale & A & 10.060 ha \\
Numero di patch & NP & 4414 \\
\hline Dimensione media dei patch & MPS & 0,26 ha \\
Densità totale & TE & $682.522 \mathrm{~m}$ \\
\hline Densità dei margini & ED & $740,3 \mathrm{~m} / \mathrm{ha}$ \\
Indice di forma media & MSI & 1,93 \\
\hline Dimensione media frattale dei patch & MPFD & 1,18 \\
Dimensione media frattale dei patch, pesata sull'area & AWMPFD & 1,13 \\
\hline Indice di diversità di Shannon & SDI & 1,62 \\
Indice di eterogeneità di Shannon & SEI & 0,69
\end{tabular}

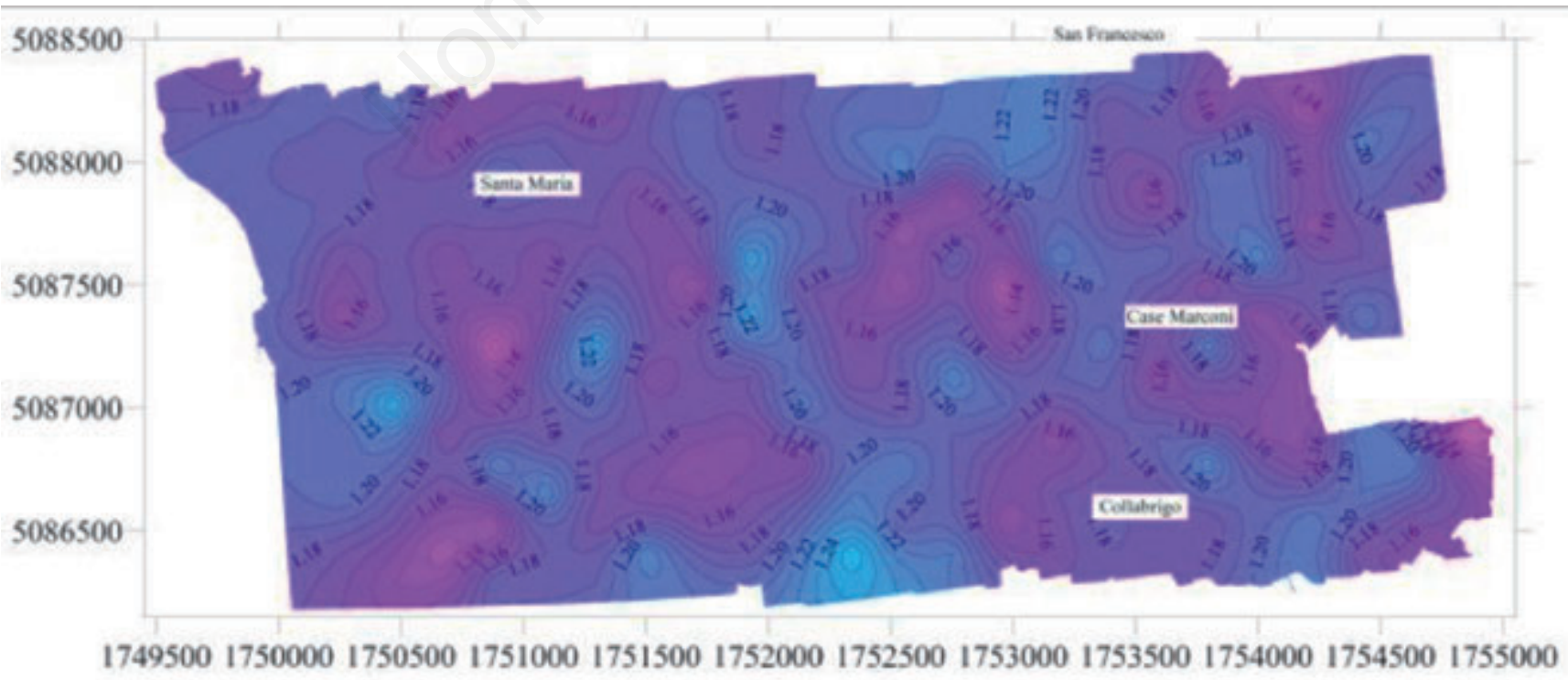

Figura 23. Dimensione Media Frattale dei Patch (MPFD). I valori piuttosto bassi indicano che il territorio è costituito prevalentemente da patch con perimetri di forma regolare, non tortuosa. 
ambiente naturale. Il limite superiore del suolo è quello con l'aria, oppure con acqua poco profonda, piante, o materie vegetali che non hanno cominciato a decomporsi. Il limite più basso, cioè che si trova al di sotto del suolo e che separa il suolo da ciò che non è suolo, è più difficile da definire. Comunemente, nella parte più bassa il suolo sfuma gradualmente verso la roccia dura o verso materiali terrosi virtualmente privi di animali, radici o di altri segni di attività biologica. A scopo di classificazione, il limite più basso di terreno è posto arbitrariamente a 200 centimetri. Il suolo consiste di orizzonti vicino alla superficie della terra che, contrariamente al materiale sottostante da cui deriva (detto: materiale genitore), sono stati alterati nel tempo dalle interazioni del clima, del rilievo e degli organismi viventi."

Poiché si tratta di un mezzo poroso, il suolo consente il movimento dell'acqua e possiede un'atmosfera interna che permette la vita sia alla flora sia alla fauna (soprattutto microrganismi e invertebrati); per questo motivo può essere considerato come un corpo vivente. Il suolo interagisce dinamicamente con l'atmosfera, la litosfera, l'idrosfera e la biosfera ed esprime molte "funzioni" di interesse vitale. Esso contiene la maggior parte di biomassa vivente presente sulle terre emerse e sostiene la vita delle piante e degli animali negli ecosistemi terrestri; esercita l'azione di filtro biologico e di trasformazione di sostanze di vario tipo; è elemento essenziale del paesaggio e regola la stabilità dei bacini imbriferi; esercita la funzione di riserva genetica e di conservazione del patrimonio archeologico e paleontologico; svolge una funzione volano nei cambiamenti della qualità dell'aria e dell'acqua, supporta gli insediamenti umani ed è fonte di materie prime (minerali, inerti, ecc.).

L'orizzonte superficiale del suolo è generalmente più ricco dei sottostanti in sostanza organica ed è sede di intensi processi di alterazione e trasformazione. Le acque meteoriche percolanti asportano e trasferiscono minerali e sostanza organica dagli orizzonti superficiali (eluviazione), verso i sottostanti orizzonti in cui prevalgono i processi di accumulo (illuviazione). All'orizzonte di accumulo segue generalmente un orizzonte di transizione verso il substrato inalterato. I caratteri più rilevanti del suolo sono la composizione mineralogica, la tessitura (determinata dalla percentuale di sabbia, limo argilla), lo stato di aggregazione delle particelle primarie (struttura), la resistenza degli aggregati alla disgregazione, il colore, la presenza di frammenti grossolani (scheletro), il drenaggio interno, lo spessore, l'attività biologica (animale e vegetale).

Il processo di formazione del solo (pedogenesi), è determinato da cinque fattori intercorrelati: il clima; gli organismi viventi, il materiale parentale (roccia, sedimenti, e materiale minerale che deriva dal disfacimento di roccia ), la topografia e il tempo.

\section{Il degrado del suolo}

In genere, i processi pedogenetici sono molto lenti; occorrono da centinaia a migliaia di anni per la formazione di pochi centimetri di suolo. Pertanto, in relazione alla lentezza del processo di alterazione del substrato, il suolo è da considerarsi come risorsa non rinnovabile (Kendall e Pimentel, 1994; Stallard, 1995).

In modo particolare si può affermare che quando i tassi di alterazione del substrato sono lenti, qualsiasi perdita di suolo superiore a $1 \mathrm{t} \mathrm{ha}^{-1}$ anno-1 $^{-1}$ può generare, in un arco di tempo compreso fra $50 \mathrm{e}$ 100 anni, un danno irreversibile a questa risorsa (EEA, 1998). Gli impatti delle attività umane sul suolo possono determinarne il degrado più 0 meno accentuato. Dopo anni di cattivo uso del suolo i danni arrecati possono essere di tale di entità da essere fortemente evidenti sia in termini di perdita dell'elemento suolo (affioramento di strati profondi indesiderati), sia di diminuzione di fertilità (calo di produzione), di modificazione del paesaggio (impantanamenti, modificazioni morfologiche), di biodiversità (diminuzione delle specie appartenenti alla microflora e alla fauna tellurica), ecc. Gli interventi correttivi molte volte consentono solo un parziale ripristino delle condizioni ottimali del suolo e delle sue molteplici funzioni ambientali.

\section{L'impatto dei movimenti di terra}

Negli ambienti collinari Italiani la realizzazione di nuovi impianti arborei specializzati è quasi sempre preceduta da operazioni di sbancamento, livellamento e regolarizzazione dei versanti. Queste operazioni, consigliate indiscriminatamente dagli agronomi (Morando, 2001), sono finalizzate all'ottimizzazione economica, in quanto superfici ampie e a pendenza uniforme diminuiscono i tempi di esecuzione delle operazioni agricole. Su versanti a pendenza più accentuata, ove non si possono realizzare impianti a rittochino (con i filari lungo la massima pendenza), la realizzazione dei terrazzi e dei ciglionamenti rappresenta l'unico modo ritenuto attualmente valido per realizzare una viticoltura specializzata.

In entrambi i casi gli sbancamenti provocano il movimento e la ridistribuzione lungo i versanti di enormi quantità di suolo e possono indurre seri danni all'ecosistema (Figura 24). L'alterazione della morfologia originale di vaste aree può rappresentare di per sé un grave danno, quando impatta negativamente sul valore estetico del paesaggio e sulla biodiversità (vedi le considerazioni sui risultati forniti dalla analisi del paesaggio). La modificazione dello spessore e del profilo originario del suolo può determinare lo sconvolgimento dell'equilibrio idrogeologico, aumentando la vulnerabilità del suolo all'erosione idrica. Nelle zone dove i mezzi meccanici asportano il suolo possono affiorare orizzonti profondi 0 perfino la roccia madre. In genere questi materiali non hanno caratteristiche favorevoli alla vita delle piante. Essi possono limitare fortemente l'approfondimento degli apparati radicali e sono caratterizzati da ridotto contenuto di sostanza organica e di nutrienti. La strutturazione di questi materiali è assente, i volumi di acqua disponibile sono bassi e l'attività biologica è scarsissima. Nelle zone di accumulo dei materiali terrosi trasportati dai bulldozer il suolo si presenta senza organizzazione interna, compattato dalle macchine operatrici, ma sostanzialmente non consolidato e vulnerabile a tutte le forme di erosione (frane superficiali, erosione incanalata e sotterranea). Il rischio di erosione nelle aree collinari livellate è molto alto, tenuto conto che le operazioni meccaniche di livellamento sono effettuate durante la stagione estiva, caratterizzata da precipitazioni intense, a cui fanno seguito le abbondanti e prolungate piogge autun-

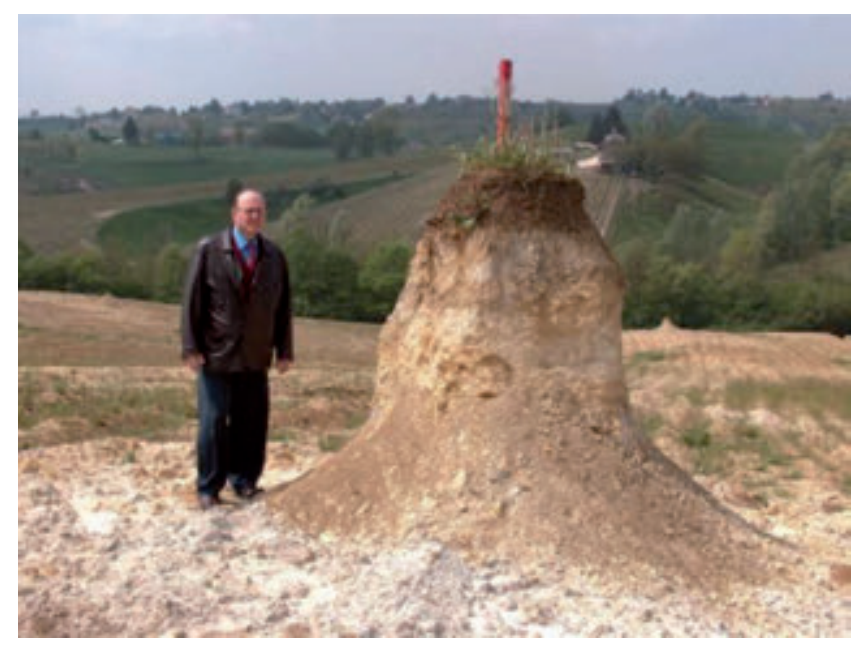

Figura 24. Uno sbancamento effettuato nell'area di studio, pari a circa 34,000 t/ha di suolo asportato. Le colonne di suolo residuali, nelle quali sono ancora riconoscibili gli orizzonti, sono state lasciate sul campo dal ruspista per dimostrare il lavoro effettuato. Esse testimoniano che il suolo è stato asportato completamente, fino ad una profondità di più di 2 metri, su una superficie molto vasta. 
nali (Bazzoffi e Pellegrini, 1992; Grimm et al., 2001).

Ricerche svolte nell'ambiente collinare dell'Emilia Romagna hanno dimostrato che pochi temporali estivi possono causare, su aree livellate, perdite di suolo superiori a $500 \mathrm{Mg} \mathrm{ha}^{-1}$ (Bazzoffi et al., 1989). In una zona collinare della Toscana (San Gimignano, Siena) hanno evidenziato perdite di suolo di $149 \mathrm{t} \mathrm{ha}^{-1}$ in seguito ad un evento piovoso autunnale di $82 \mathrm{~mm}$ (Bazzoffi et al., 2006). La forte erosione del suolo che segue gli sbancamenti determina forti immissioni di sedimenti nel reticolo idrografico, con danni a distanza agli insediamenti umani, alle infrastrutture e all'ambiente.

Nella viticoltura collinare, l'intervento dei bulldozer non si limita alla fase di impianto. Esso viene ripetuto in fase di reimpianto dei vigneti al fine di eliminare le vecchie piante e rendere nuovamente uniforme la superficie del suolo. Sui versanti a rittochino, la situazione di degrado del suolo si aggrava, nel periodo di gestione successiva all'impianto, a causa dell'erosione idrometeorica. Le acque trovano facilità di scorrimento su versanti lunghi ed uniformi; principalmente lungo le zone compattate dalle ruote o dai cingoli dei trattori (Figura 26).

\section{Impatto degli sbancamenti preparatori agli impianti dei vigneti sulla risorsa suolo e sulla morfologia dei versanti}

\section{Premessa}

Per determinare l'impatto degli sbancamenti sul suolo e sulla morfologia dei versanti è stata condotta una analisi su un campione di vigneti, di recente costituzione, situati nell'area di Conegliano di Valdobbiadene e di Asolo, sia su impianti a rittochino che a traverso.

L'impatto sulla risorsa suolo è stato valutato attraverso un'analisi quantitativa sui volumi di materiale terroso mobilizzati a seguito dell'intervento dei bulldozer. L'impatto sul paesaggio è stato valutato attraverso la quantificazione delle aree soggette a sbancamento e rimodellamento del suolo. Per questa analisi si è adottata una metodologia di indagine nuova.

È importante precisare che sia riguardo all'impatto sulla risorsa suolo sia riguardo alle modificazioni del paesaggio, l'indagine si è limitata alla quantificazione dei fenomeni, senza entrare nel giudizio di merito sull'opportunità di realizzazione di questi interventi. Tale compito, infatti, spetta al decisore politico, sulla base di una serie di valutazioni socio-economiche e di sostenibilità ambientale fra le quali possono risultare utili anche i dati forniti dalla presente indagine.

\section{Impatto sulla risorsa suolo}

Per questo studio si è utilizzata una metodologia comunemente usata per evidenziare le variazioni di quota del terreno a seguito di eventi di varia natura; ad esempio a seguito di erosione del suolo, di frane, bradisismi, ecc. (Frazier e McCool, 1981; Whiting et al., 1987). Essa consiste nella comparazione diacronica di modelli digitali del terreno (DTM), cioè sulla comparazione delle quote superficiali del suolo prima e dopo l'evento di perturbazione. I DTM originale sono stati prodotti utilizzando la cartografia esistente (CTR 1:5000 della Regione Veneto) realizzata per mezzo di foto aeree (volo 1991) con tecniche fotogrammetriche. Per ottenere le quote, lo strato vettoriale delle CTR è stato trasformato in shp-file di punti quotati. I DTM di comparazione, ovvero della superficie del terreno al 2007, sono stati realizzati con rilievo celerimetrico a terra in alta precisione utilizzando un GPS geodetico Leica 1200. Il rilievo è stato condotto su nove vigneti campione, utilizzando per ciascuno di essi una maglia regolare di 5 metri.

Per rendere compatibili, rispetto alle quote, le misure rilevate nel 2007 rispetto a quelle derivanti dai CTR, le quote rilevate sono state corrette tramite rilievo di precisione dei caposaldi della Regione Veneto, che furono utilizzati per la produzione delle CTR.

Il rilevo delle quote per i vigneti selezionati è consistito di tre fasi: 1) individuazione e georeferenziazione di precisione di un punto stabile di riferimento, in vicinanza di ciascun vigneto, con tempi di stazionamento di 30 minuti in modalità GPS statico; per l'allacciamento del punto al sistema UTM si sono utilizzati i punti GPS IGM95, scelti tra i più prossimi a ciascun vigneto da rilevare. L'approssimazione delle

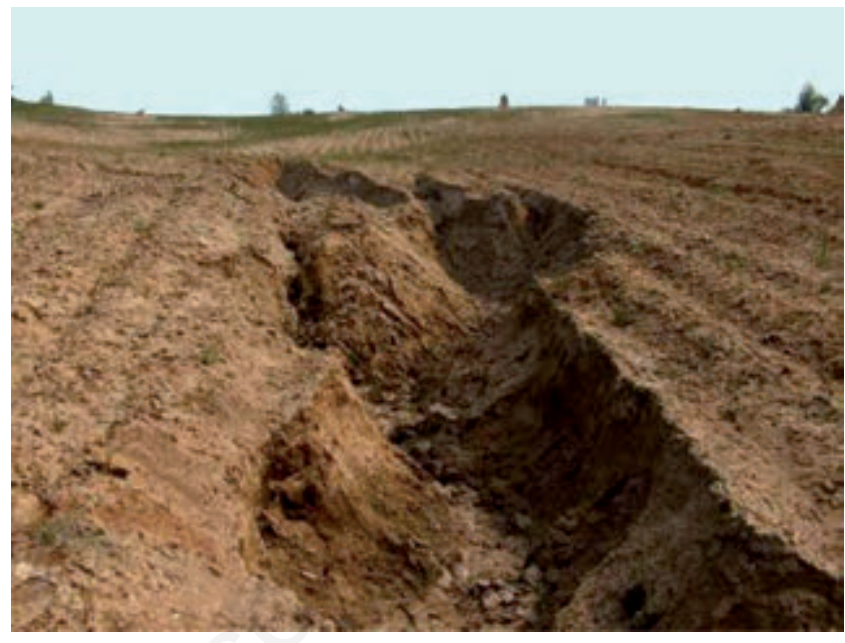

Figura 25. Forte erosione per burronamento su accumuli terrosi a seguito di sbancamenti. Si tratta della medesima superficie della Figura 24.

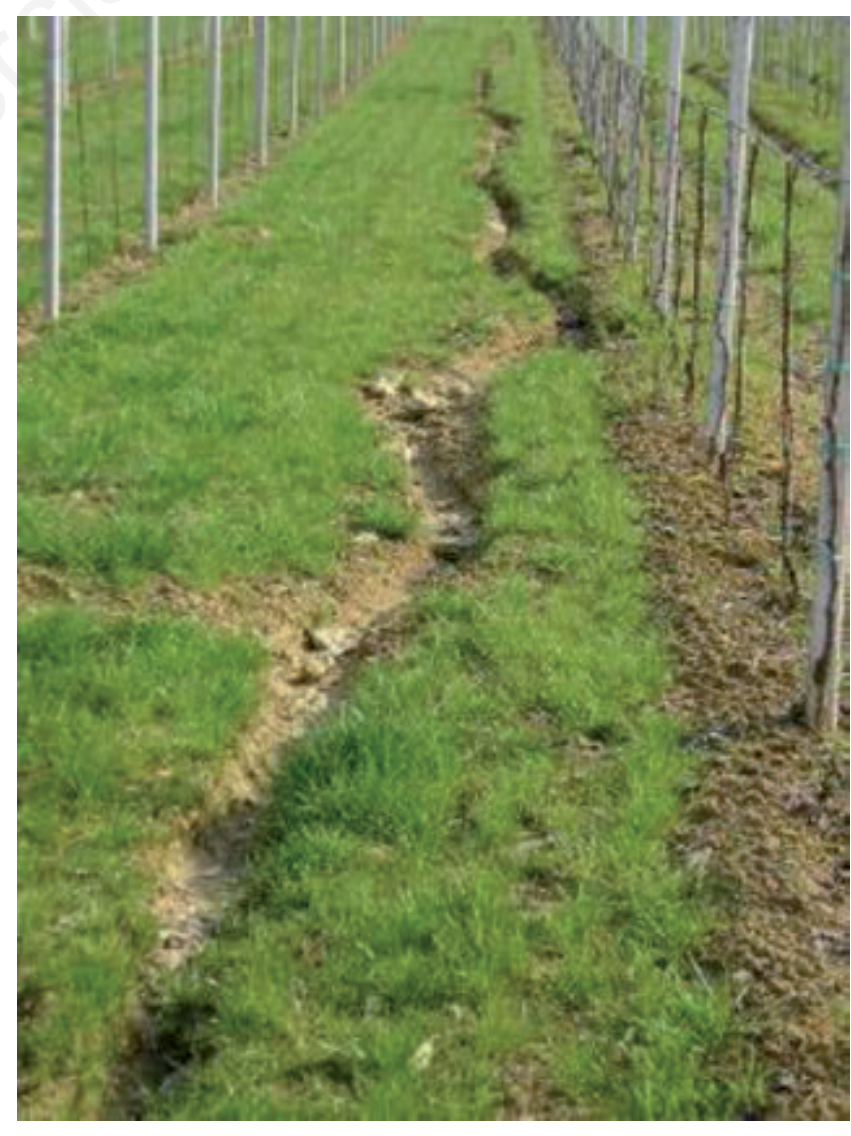

Figura 26. Erosione incanalata per rigagnoli in un vigneto nell'area di Conegliano. 
quote altimetriche ellissoidiche a quelle geodetiche locali (m s.l.m.) è stata realizzata utilizzando i grigliati ed il software Verto3 forniti dall'IGM; 2) Per ciascun vigneto, mediante centramento forzato, si è messo in stazione l'antenna del ricevitore GPS-base sul punto stabile di riferimento precedentemente inquadrato; infine, 3) con il ricevitore GPS rover in modalità RTK, si è provveduto a rilevare i punti al suolo all'interno del vigneto.

I DEM, con celle di 0,5 m, sono stati ricavati utilizzando la funzione di interpolazione Kriging in ArcGis. Gli spessori di sbancamento e quelli di accumulo di materiali terrosi sono stati ricavati attraverso la sottrazione dei DTM risalenti al 1991dai DTM al 2007.

I valori negativi evidenziano che nel 1991 le quote erano più elevate rispetto al 2007 e che quindi il suolo è stato asportato. Invece, dove i valori sono risultati positivi è stato effettuato un accumulo di materiale terroso.

L'operazione di sottrazione dei due DEM è stata eseguita in ambiente ArcGis 9 tramite la funzione Raster Calculator in Spatial Analyst. Per l'analisi statistica dei dati i DEM degli scavi e riporti sono stati ricampionati con una dimensione di cella pari a 2 metri e quindi convertiti in file di testo (XYZ).

\section{Risultati}

Nelle Figure dalla 27 alla 32 , sono riportati le misure degli scavi e dei riporti avvenuti a seguito dei movimenti di terra su alcune aree a vigneto nell'area di Conegliano. Nelle Figure 33, 34 e 35 vengono mostrati i valori di scavo e riporto su aree sbancate, e successivamente

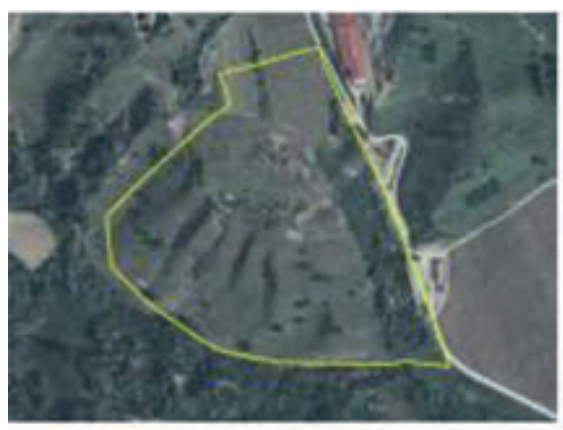

Figura 27. Un'area sodiva prima dello sbancamento.

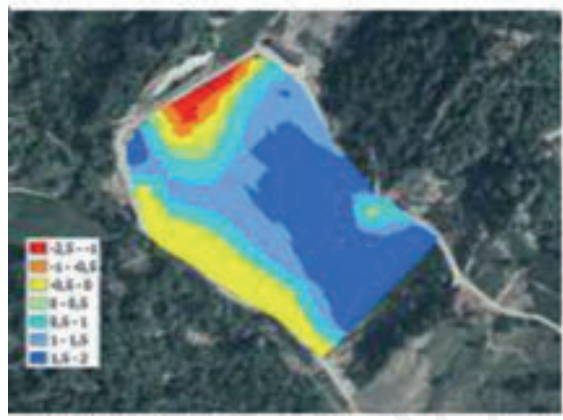

Figura 30. Sbancamento nell'area di Conegliano. Scavi e riporti $(\mathrm{m})$.

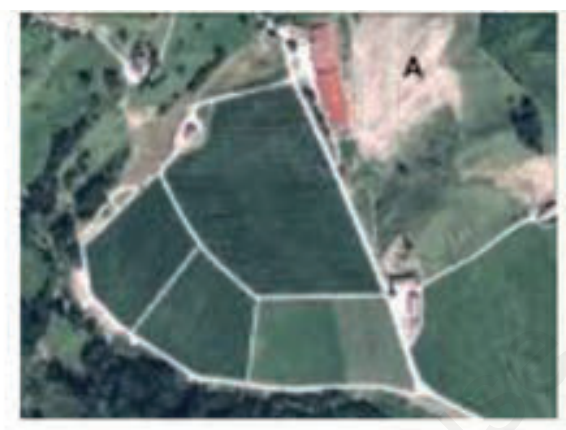

Figura 28. La medesima area dopo lo sbancamento e l'impianto del vigneto. Si noti la cava di prestito di terreno (indicata con la lettera A).

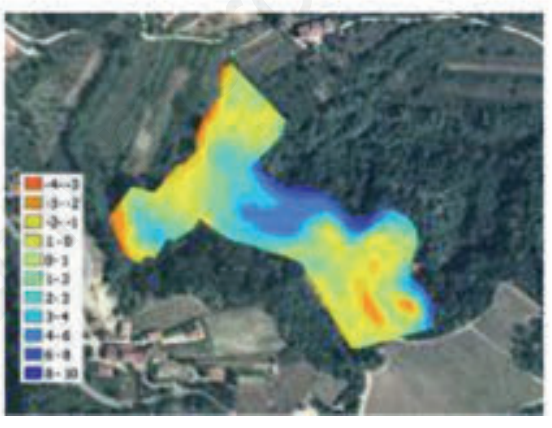

Figura 31. Sbancamento nell'area di Conegliano. Scavi e riporti (m).

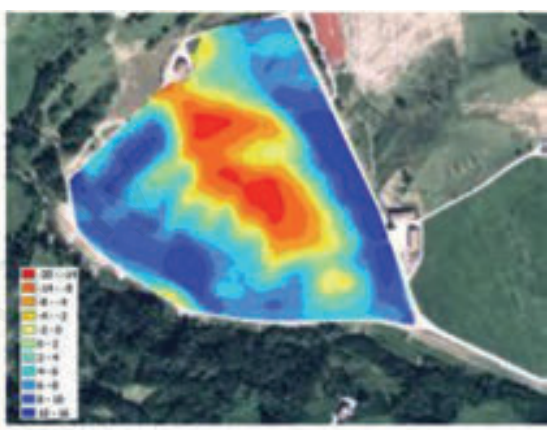

Figura 29. Spessori di suolo movimentati. Scavi e riporti $(\mathbf{m})$.

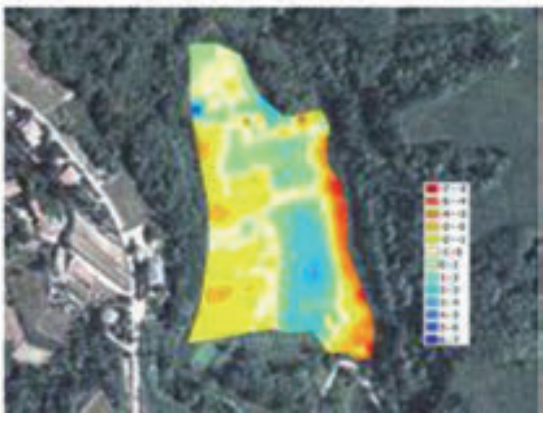

Figura 32. Sbancamento nell'area di Conegliano. Scavi e riporti $(\mathrm{m})$.

Tabella 4. Statistiche descrittive dei valori di scavo e riporto sui punti campionari (distanza 2 m) ricavati dai GRID delle differenze altimetriche (la numerazione dei vigneti è casuale).

\begin{tabular}{lcccccccccccc} 
& Vigneto 1 & Vigneto 2 & Vigneto $\mathbf{3}$ & Vigneto 4 & Vigneto 5 & Vigneto 6 & Vigneto 7 & Vigneto 8 & Vigneto 9 Tutti \\
Area (ha) & 0,07 & 0,15 & 4,13 & 0,92 & 1,58 & 4,23 & 11,20 & 3,07 & 2,93 & 28,27 \\
N. campioni & 171 & 368 & 10,317 & 2307 & 3941 & 10,582 & 27,996 & 7663 & 7331 & 70,676 \\
\hline Media & 3,46 & 2,00 & 0,09 & 0,20 & $-1,43$ & 6,14 & 2,66 & 1,20 & 4,07 & 2,49 \\
Mediana & 3,39 & 1,97 & $-0,04$ & 0,36 & $-1,24$ & 6,90 & 4,95 & 0,60 & 4,02 & 2,45 \\
\hline Dev. standard & 1,06 & 0,61 & 1,09 & 1,77 & 1,84 & 3,38 & 7,13 & 2,26 & 1,62 & 5,24 \\
Moda & 2,43 & 1,94 & $-0,17$ & 0,52 & 0,30 & 9,47 & 6,27 & $-0,30$ & 3,28 & 0,30 \\
\hline Minimo & 1,38 & 0,28 & $-2,46$ & $-4,22$ & $-5,35$ & $-3,05$ & $-18,93$ & $-4,72$ & $-2,86$ & $-18,93$ \\
Massimo & 5,36 & 3,35 & 5,35 & 3,58 & 1,92 & 12,16 & 15,62 & 9,95 & 11,05 & 15,62 \\
\hline Curtosi & $-1,17$ & $-0,61$ & 3,82 & $-0,54$ & $-1,24$ & $-0,59$ & 0,14 & 0,54 & 0,70 & 1,45 \\
Asimmetria & 0,05 & $-0,09$ & 1,47 & $-0,40$ & $-0,24$ & $-0,56$ & $-0,95$ & 0,81 & $-0,15$ & $-0,79$
\end{tabular}


impiantate a vigneto, nelle aree di Valdobbiadene e di Asolo. Poiché i DTM al 1991 derivano dai valori di quota delle curve di livello, i valori dei volumi di scavo e riporto, determinati nel presente studio per i 9 vigneti campione, sono affetti dal medesimo errore che deriva dal grado di precisione delle quote riportati nella Cartografia Tecnica Regionale.

I risultati mostrano che, in genere, i movimenti di terra sono piuttosto imponenti; sia in fase di messa a coltura di terreni destinati precedentemente ad altri usi, sia nel caso dei reimpianti.

Nella Figura 36 si riporta la distribuzione delle frequenze degli spessori di scavo e di riporto osservati sulla totalità dei punti campionari, derivati dai GRID delle differenze di quota. Nella Tabella 4 si riportano le statistiche descrittive relative sia alla totalità dei punti campionari sia suddivise per ciascun vigneto oggetto del presente studio.

Per garantire la privacy dei proprietari, non vengono riportate le posizioni dei vigneti sul territorio; pertanto la numerazione dei vigneti non ha relazione con le Figure dalla 27 alla 35.

\section{Considerazioni sui risultati forniti dall'analisi statistica sui livellamenti}

Le statistiche descrittive mostrano che il bilancio degli scavi e dei riporti è pari a $+2,49 \mathrm{~m} \pm 3,9 \%$ (confidenza $95 \%$ ). Ovvero, il valore medio osservato sulla globalità dei punti campionari mostra un innalzamento della superficie del suolo nelle aree interessate ai movimenti di terra.

L'analisi effettuata su ciascun vigneto (Tabella 4) mostra che l'innalzamento di quota si è verificato in quasi tutti i casi, con esclusione del vigneto n. 5. L'aspetto leptocurtico della curva di distribuzione del pool di campionamenti evidenzia un allontanamento dalla normalità distributiva, con peso più marcato della parte centrale della distribuzione rispetto alle code. Ciò significa che le classi dei valori estremi di scavo e di riporto sono poco rappresentate. La distribuzione delle frequenze mostra anche che le aree a bilancio zero, ovvero dove scavi e riporti si compensano, sono la maggioranza e coprono il $18,7 \%$ del totale. Molto estese sono anche le superfici che hanno subito variazioni di

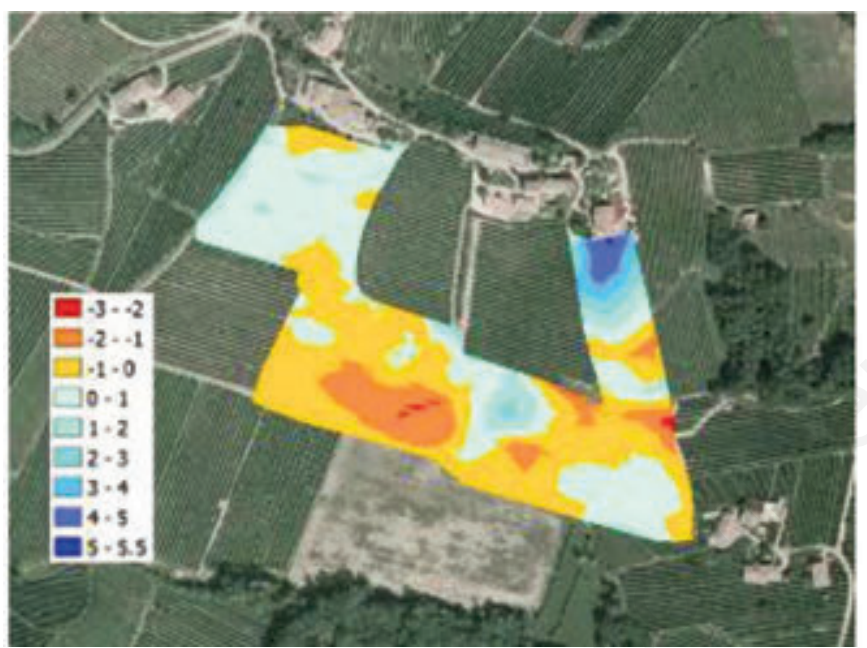

Figura 33. Sbancamento nell'area di Valdobbiadene. Scavi e riporti (m).

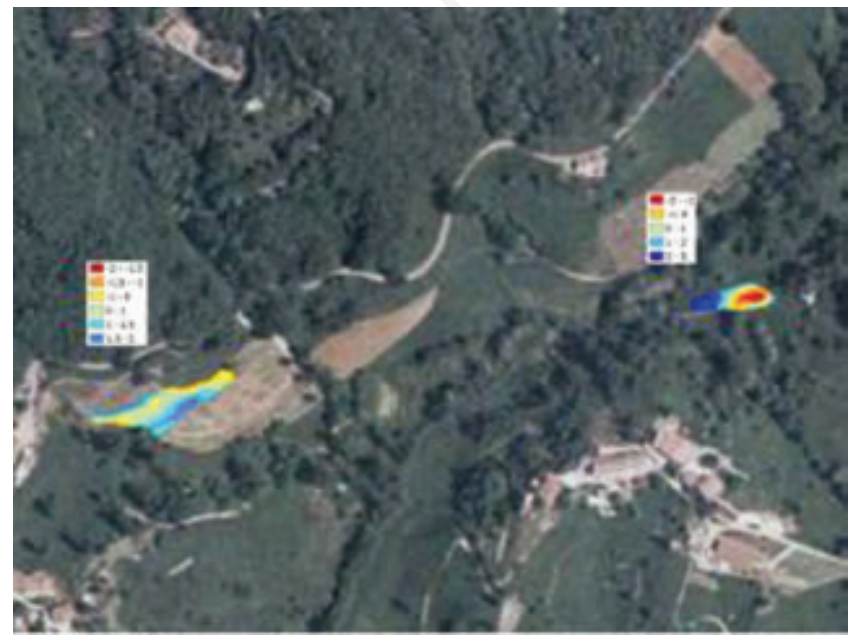

Figura 35. Sbancamenti nell'area di Asolo. Scavi e riporti (m).

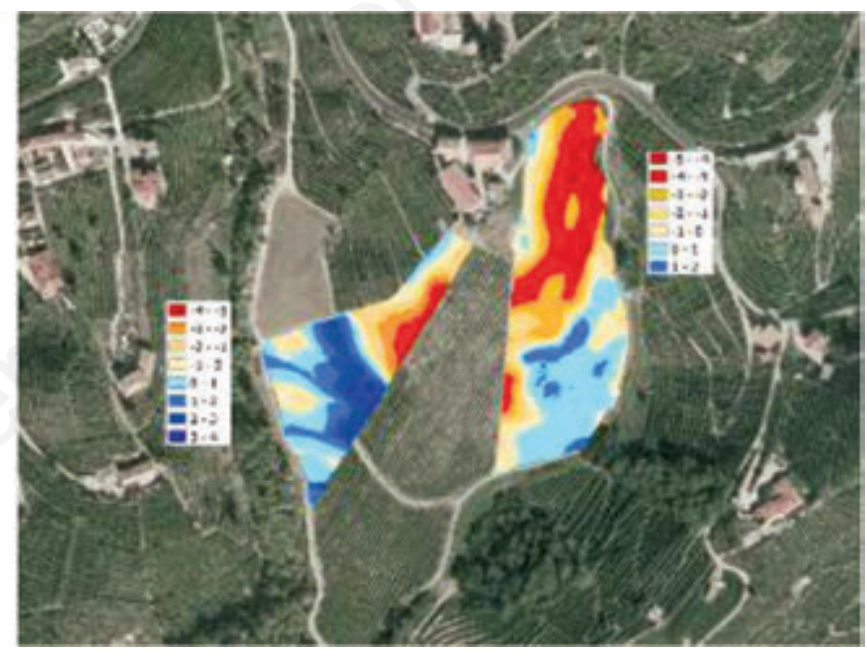

Figura 34. Sbancamento nell'area di Valdobbiadene. Scavi e riporti $(\mathbf{m})$.

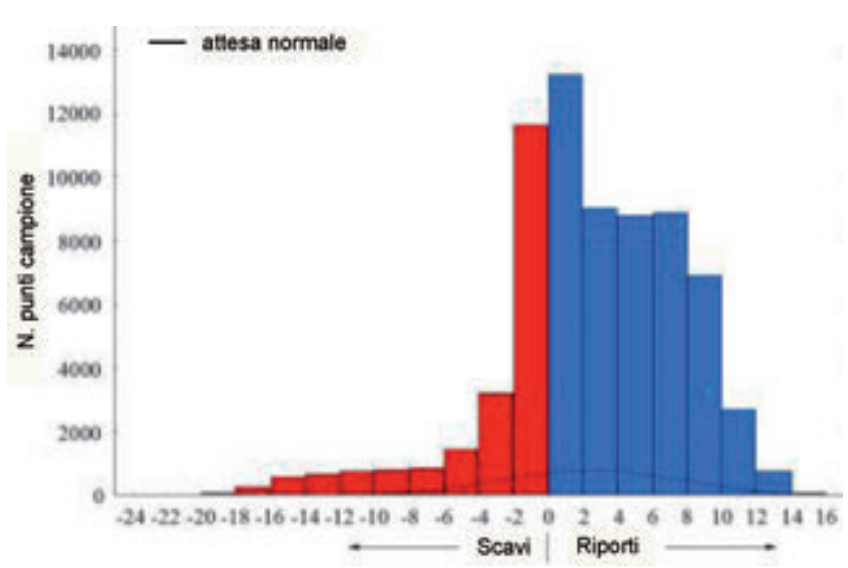

Figura 36. Distribuzione delle frequenze degli spessori di scavo e di riporto osservati sulla totalità dei punti campionari, derivati dai GRID delle differenze di quota. 
quota comprese fra +2 e -2 metri, pari rispettivamente il $16,5 \%$ e il $12,8 \%$ della superficie totale dei vigneti. Le superfici interessate da forti accumuli, compresi fra 4 e 8 metri, sono estese su una notevole superficie, pari al 34,7\% dell'area totale. Al contrario, le aree con abbassamento di superficie compreso fra 4 e 8 metri coprono il 7,9\% dell'area totale.

Da queste osservazioni si possono trarre alcune deduzioni e tentare l'interpretazione di quanto avviene a seguito degli sbancamenti. L'innalzamento medio della superficie osservato su quasi tutti i vigneti conferma quanto osservato a Pietrafitta (San Gimignano, Siena), utilizzando la medesima tecnica di indagine (Bazzoffi et al., 2006). La spiegazione di questo fenomeno osservato sui nove vigneti potrebbe risiedere in diverse cause: 1) in un errore sistematico nei valori delle quote delle CTR 1:5000 Regionali; questa ipotesi appare poco attendibile, visto che le aree a bilancio zero, ovvero dove scavi e riporti si compensano, sono la maggioranza (moda pari a 0,30 ); 2) nell'osservazione che nelle aree di accumulo il terreno possiede una massa volumica più bassa rispetto al suolo prima della rimozione, quindi occupa un volume maggiore; 3) un'altra parziale spiegazione potrebbe risiedere nel riporto di terreno prelevato da terreni limitrofi; anche se sembra poco realistico che ciò sia avvenuto in quasi tutti i vigneti.

Tutte le suddette concause non appaiono sufficientemente convincenti a spiegare il fenomeno del prevalere di un innalzamento di quota nelle aree soggette a movimento di terra. Lo studio ha comunque evidenziato che gli spessori di materiali terrosi movimentati possono essere molto rilevanti, ed in grado di modificare notevolmente la condizione originaria del suolo e del paesaggio.

\section{Analisi areale dell'impatto degli sbancamenti sulla morfologia dei versanti}

Mentre nei capitoli precedenti sono stati evidenziati gli impatti degli sbancamenti sul valore estetico del paesaggio e sulla risorsa suolo, nel presente capitolo si propone una metodologia per l'individuazione delle aree che hanno subito sbancamento, al fine di quantificare l'influenza di queste pratiche agronomiche nella modificazione "massiva" del paesaggio, ovvero alle diverse scale geografiche e amministrative: di bacino idrografico, oppure comunale, provinciale o regionale.

Anche in questo studio non vengono espressi giudizi di merito sulla necessità degli interventi e sulla positività 0 negatività in termini di sostenibilità ambientale e socio-economica. Si è inteso fornire strumenti al decisore politico per il buon governo del territorio e soprattutto per la valorizzazione del paesaggio del vino.

\section{Individuazione delle aree rimodellate}

Il problema dell'individuazione delle aree soggette a rimodellamento superficiale è stato affrontato tramite un approccio morfologico, partendo dal presupposto che le aree che hanno subito sbancamenti sono caratterizzate da un profilo regolare delle pendici.

Nel caso dei vigneti impiantati a rittochino i versanti si presentano come piani inclinati, con curve di livello che si dispongono in modo equidistante e parallelo. Anche nei terreni sbancati e sistemati a terrazzi si osserva il medesimo andamento delle curve di livello; infatti esse si sviluppano parallelamente sui piani (terrazzi) o sui ciglioni fra terrazzo e terrazzo. Nelle aree non soggette a sbancamento la morfologia naturale è rappresentata da curve di livello che solo sporadicamente assumono andamento quasi esattamente parallelo.

La metodologia che viene qui proposta consiste nel discriminare le aree con curve di livello dotate di un elevato grado di parallelicità rispetto alle aree che non soddisfano questo requisito. Per l'individuazione di queste aree si è calcolato l'indice di Curvatura Del Profilo utilizzando, in ambiente Surfer v.8.02, il modulo Profile Curvature dal menù Grid Calculus. La curvatura del profilo determina il tasso di cam- biamento della pendenza, a monte 0 a valle, lungo la direzione della massima pendenza. Per ogni punto del GRID, il modulo Profile Curvature produce linee di isocurvatura, cioè di cambiamento costante di pendenza. Valori negativi indicano una convessità del profilo mente valori positivi denotano una convessità. Il valore zero indica una superficie a profilo costante, anche se inclinata.

La metodologia per l'individuazione delle aree livellate in zone collinari si basa su due elementi: 1) sul fatto oggettivo, derivante dall'evidenza matematica, che una superficie collinare o montana, caratterizzata da linee di isocurvatura parallele, ossia con profilo di curvatura prossimo a zero, sia un piano inclinato lungo un versante; 2) sull'assunto che tale morfologia sia stata causata da un rimodellamento del profilo del terreno di origine antropica, in quanto caratterizzata da una forte discontinuità rispetto alla morfologia circostante che possiede valori elevati di curvatura del profilo.

Per procedere con questo tipo di analisi è stato necessario dimostrare che un basso valore dell'indice di curvatura associato a una morfologia non pianeggiante è correlato con la presenza di vigneti livellati. A tal fine, per ciascun poligono d'uso del suolo (Figura 1), è stata determinata la pendenza media e il valore medio della curvatura di profilo. Successivamente è stato costruito un modello mettendo in correlazione questi due parametri con la variabile categoriale (Vigneto, Area naturale). Il modello è stato quindi applicato ad un gruppo di 39 vigneti esterni all'area utilizzata per la costruzione del modello stesso. In tal modo è stata verificata la capacità del modello di evidenziare i vigneti collinari, ove è presumibile che fosse stato effettuato lo sbancamento ed il rimodellamento del terreno. Per lo sviluppo della metodologia, è stato ricavato il GRID della pendenza dai GRD delle quote derivanti dalle CTR 1:5000. Si è utilizzato il modulo Surface, Derive Slope in ambiente ArcMap. In ambiente Surfer 8.02, sul medesimo GRD delle quote, è stato ricavato il GRD della curvatura del profilo del terreno. Successivamente, in ambiente ArcMap, con il comando AnalisysSummarize zones, si sono determinate, per ciascun poligono d'uso del suolo, la pendenza media e il valore medio della curvatura di profilo. Fra i poligoni d'uso del suolo sono stati selezionati solo i Vigneti e le Aree naturali (boschi, fasce boscate) ottenendo un totale di 351 aree che sono servite per costruire un modello di previsione. Il modello è stato sviluppato utilizzando il modulo Reti Neurali di Statistica v.7.0 (StatSoft). Sono stati utilizzati 231 casi per l'addestramento, 60 casi test e 60 casi di selezione. Il miglior modello è risultato una Funzione a Base Radiale (RBF) di classificazione, che combina un singolo strato nascosto di unità radiali con uno strato di output a funzione discriminante, come illustrato in Figura 37. La performance della rete è risultata accettabile. Infatti, nel 78,3\% dei casi essa ha attribuito ai poligoni

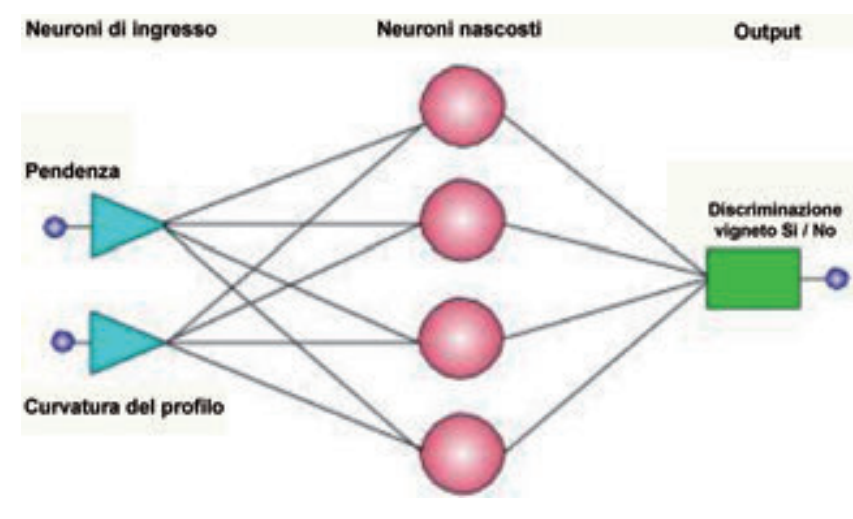

Figura 37. Grafico della rete neurale sviluppata per la discriminazione delle aree livellate. 


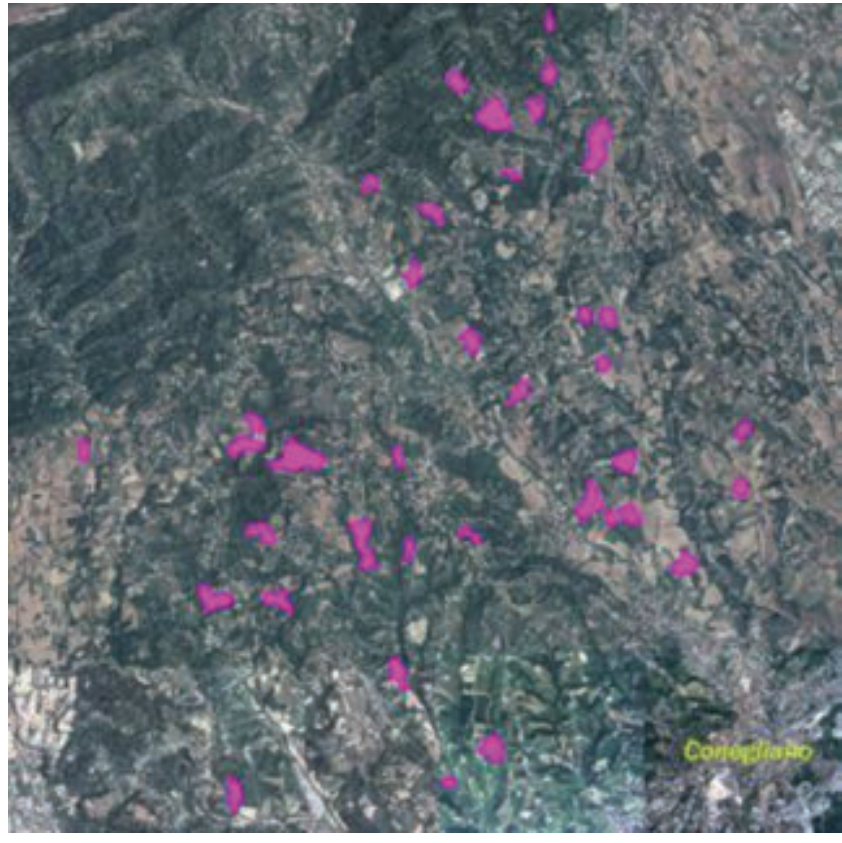

Figura 38. Localizzazione dei Vigneti utilizzati per la verifica della capacità diagnostica delle rete neurale.

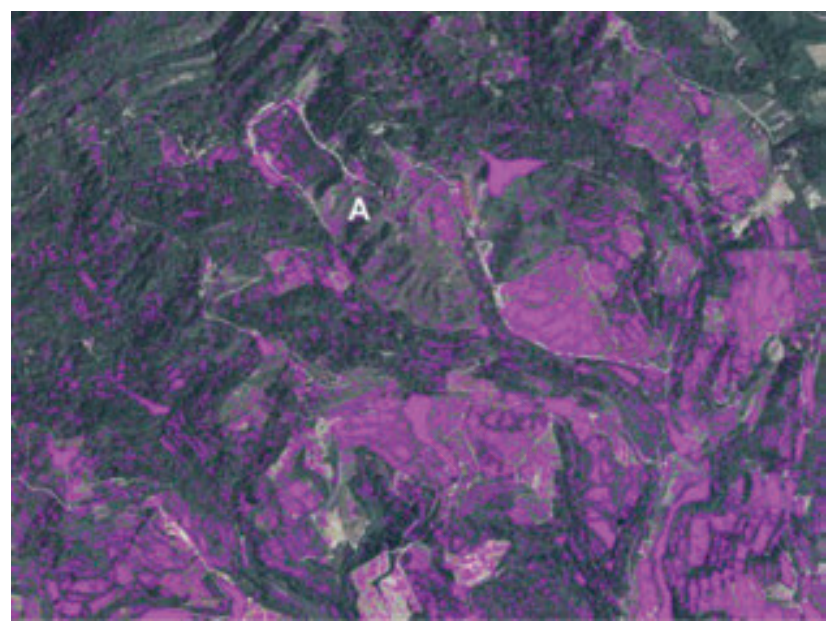

Figura 39. Raster della curvatura di profilo riferito al 1991 su foto aeree al 2001. Si notino le aree a vigneto con curvatura bassa (in viola) che, molto verosimilmente, hanno subito sbancamenti e rimodellamenti del terreno. Con la lettera " $A$ " è indicata la zona corrispondente ai vigneti delle Figure 28 e 30 . In tali zone la curvatura è alta in quanto nel 1991 ancora non erano stati realizzati i vigneti. alla giusta classe categoriale, come illustrato nella Tabella 5 .

Nella Figura 38 viene mostrata la mappa dei vigneti utilizzati per la verifica della bontà del modello previsionale. I risultati dell'applicazione della rete neurale ai 39 vigneti (Tabella 6 ) mostrano che nel $92 \%$ dei casi il modello neurale è stato in grado di evidenziare le aree dove è avvenuto il livellamento del terreno. Sovrapponendo il raster della curvatura di profilo riferito al 1991 su foto aeree più recenti, risalenti al 2001, si possono mettere in evidenza le aree con curvatura bassa e con uso del suolo a vigneto, le quali, molto verosimilmente, hanno subito sbancamenti e rimodellamenti del terreno (Figura 39). L'evidenziazione di tali aree è stato effettuato visualizzando solo i valori molto bassi della curvatura di profilo, nel range da $-0,0006 \mathrm{a}+0,0006$.

Considerazioni sui risultati forniti dall'analisi areale dell' impatto degli sbancamenti sulle forme del paesaggio

Per una valutazione complessiva dell'impatto degli sbancamenti sul "paesaggio del vino", inteso non solo per il suo valore estetico ma anche per le funzioni ambientali ed economiche che esprime, occorrerebbe estendere a tutto il territorio sia l'analisi morfologica quantitativa del valore del paesaggio, sia l'analisi areale della curvatura del profilo del terreno.

Questi due strumenti di analisi geografica del territorio, insieme con l'analisi degli spessori di sbancamento e di riporto, consentono la quantificazione e la localizzazione degli impatti; che opportunamente utilizzati da ulteriori strumenti di analisi di VIA, possono concorrere ad assumere decisioni consapevoli di governo del territorio.
Tabella 5. Risultato del test di performance della rete neurale.

\begin{tabular}{lcc} 
& $\begin{array}{c}\text { Vigneti } \\
\text { (morfologia } \\
\text { livellata) }\end{array}$ & $\begin{array}{c}\text { Aree con morfologia } \\
\text { naturale } \\
\text { non livellata }\end{array}$ \\
Casi & 207 & 144 \\
Attribuzione corretta & 165 & 110 \\
\hline Attribuzione sbagliata & 42 & 34 \\
Corretta (\%) & 79.7 & 76.4 \\
\hline Sbagliata (\%) & 20.3 & 23.6 \\
Totale (\%) & 100 & 100 \\
\hline
\end{tabular}

Tabella 6. Validazione della bontà della rete neurale attraverso la sua applicazione a 39 vigneti test non utilizzati per produrre il modello.

\begin{tabular}{lccc} 
Classe osservata & Numero di aree & Numero assegnavioni corrette & Numero assegnavioni errate \\
Area naturale & 6 & 6 & 0 \\
Vigneto & 33 & 29 & 4 \\
& & & (scambiate per aree naturali) \\
\hline
\end{tabular}




\section{Bibliografia}

Agnoletti M, Cargnello G, Gardin L, Santoro A, Bazzoffi P, Sansone L, Pezza L, Belfiore N, 2011. Traditional landscape and rural development: comparative study in three terraced areas in northern, central and southern Italy to evaluate the efficacy of GAEC standard 4.4 of cross compliance. Ital. J. Agron. 6(s1):e16.

Barocchi R, 2005. La pianificazione del paesaggio. Esperienze nel FriuliVenezia Giulia, Quaderni del Centro Studi Economici Politici. Ezio Vanoni, Trieste, Anno XII n. 3-4.

Bazzoffi P, Abbattista F, Vanino S, Pellegrini S, 2006. Impact of land levelling for vineyard plantation on soil degradation in Italy. B. Soc. Geol. Ital. Vol. Speciale 6:191-199.

Bazzoffi P, Chisci G, Missere D, 1989. Influenza delle opere di livellamento e scasso sull'erosione del suolo nella collina Cesenate. Riv. Agron. 23:213-221.

Bazzoffi P, Gardin L, 2011. Effectiveness of the GAEC standard of cross compliance retain terraces on soil erosion control. Ital. J. Agron. 6(s1):e6.

Bazzoffi P, Pellegrini S, 1992. Caratteristiche delle piogge influenti sui processi erosivi nel periodo 1964-1990 in un ambiente della valle dell'Era (Toscana). Evoluzione climatica e modelli previsionali. Annali Istituto Sperimentale per lo Studio e la Difesa del Suolo 20:161-182.

Bazzoffi P, Tesi P, 2011. Effectiveness of the GAEC standard of cross compliance Prohibition of performing unauthorized land levelling on soil erosion control. Ital. J. Agron. 6(s1):e4.

Daniel TC, Roster RS, 1976. Measuring landscape esthetics: the scenic beauty estimation method. USDA Forest Service Re-search Paper RM1.67. Rocky Mountain Forest and Range Experiment Station, Ft. Collins, CO, USA.

EEA, 1998. Europe's environment: the second assessment. Web: http:/www.eea.europa.eu/publications/92-828-3351-8

Frazier BE, McCool DK, 1981. Aerial photography to detect rill erosion. T. ASAE 24:1168-1171.

Grimm M, Jones RJA, Montanarella L, 2001. Soil erosion risk in Europe. European Soil Bureau, Institute for Environment \& Sustainability, JRC Ispra, Luxembourg. Web: http:/www.envedu.gr/Documents/Soil\%20Erosion\%20Risk\%20in\%20Europe.pdf

Henle K, Davies KF, Kleyer M, Margules C, Settele J, 2004. Predictors of species sensitivity to fragmentation. Biodiv. Conserv. 13:207-251.

Kendall HW, Pimentel D, 1994. Constraints on the expansion of the global food supply. Ambio 23:198-205.

McGarigal K, Marks BJ, 1995. Fragstats: Spatial Pattern analysis program for quantifying landscape structure. Technical Report PNW-GTR-351. USDA Forest Service.

Metzger W, 1984. I fondamenti della psicologia della Gestalt. Giunti-Barbera Ed., Firenze (ediz. originale 1963).

Morando A, 2001. Vigna nuova, materiali e tecniche per l'impianto del vigneto. Ed. Vit.En., Calosso d'Asti (AT).

Soil Survey Staff, 1999. Soil taxonomy. A basic system of soil classification for making and interpreting soil surveys (Second Edition). Agriculture Handbook Number 436. US Department of Agriculture, Natural Resources Conservation Service.

Stallard RF, 1995. Tectonic, environmental, and human aspects of weathering and erosion: a global review using a steady-state perspective. Annu. Rev. Earth Pl. Sc. 23:11-39.

Whiting ML, De Gloria SD, Benson AS, Wall SL, 1987. Estimating conservation tillage residue using aerial photography. J. Soil Water Conserv. 2:130-132.

\section{APPENDICE 1}

\section{LA CARTA DEL PAESAGGIO DEL VINO}

A Cividale, in un seminario tenutosi nell'ambito di CIVINTAS, viticultori, agronomi, amministratori, architetti e specialisti del paesaggio si sono accordati su alcune regole per un buon paesaggio del vino.

Questo storico accordo fra categorie spesso contrapposte è avvenuto grazie a una nuova sensibilità da parte dei vignaioli più avveduti, $i$ quali sono convinti che, se si vuole restare nel mercato, non basta più produrre vino: occorre produrre anche paesaggio.

La manifestazione è nata per iniziativa dell'ISPAR - Istituto per lo studio del paesaggio e dell'architettura rurale e per la sensibilità del Comune di Cividale del Friuli che la ha ospitata. Si conta ora di presentare la Carta in un convegno in settembre e poi, se vi sarà la disponibilità da parte di Amministrazioni e d enti, potranno seguire altre iniziative, quali mostre, premi, stage per viticultori, agronomi, architetti, per produrre un paesaggio che sia una cornice adeguata al buon bere.

La carta, anche se non impegna formalmente le amministrazioni e le categorie rappresentate da coloro che la hanno sottoscritta, è il documento di una convergenza di vedute e di intenti tecnici, operatori, amministratori, che in vario modo possono esprimersi autorevolmente in materia e operare di conseguenza.

ISPAR - Istituto per lo studio del paesaggio e dell'architettura rurale

\section{CARTA DEL PAESAGGIO DEL VINO}

Concordata nel seminario sul paesaggio del vino tenutosi a Cividale il 23 giugno 2001

\section{IL BISOGNO DI PAESAGGIO}

Il paesaggio è un bisogno sociale: cerchiamo di vivere e soprattutto di passare il nostro tempo libero ove il paesaggio sia bello e coerente con le qualità del luogo.

Con l'aumento del benessere aumenta la disponibilità di tempo libero e di mezzi economici, aumenta il bisogno di cultura e anche di paesaggio.

\section{NON BASTERÀ PIÙ PRODURRE VINO}

Con l'espandersi della globalizzazione le produzioni correnti saranno sempre più decentrate: altri paesi produrranno vini a minor prezzo e con sufficiente qualità. Diminuisce la produzione di vino comune, inteso come alimento e aumenta la richieste di vino di qualità, legato al piacere della tavola e al tempo libero. Le produzioni legate al benessere e al tempo libero, come il vino, hanno sempre più bisogno di un luogo in cui si identifichino: il loro valore sarà legato anche alla qualità del paesaggio viticolo, al loisir. Sempre più viticoltori uniranno la produzione vinicola all'offerta di servizi per il tempo libero: ristorazione, degustazione, ag $\pi$ riturismo.

Il paesaggio è l'elemento essenziale di un nuovo turismo legato alla tipicità e alle eccellenze ambientali ed enogastronomiche.

\section{IL BUON PAESAGGIO NECESSARIO COMPLEMENTO DEL BUON VINO}

I viticoltori, quindi, contribuiranno a produrre paesaggio; dovranno cioè curare che il territorio in cui operano mantenga e rafforzi i caratteri di qualità formale e di identità storica che sono necessari complementi della cultura del tempo libero.

\section{QUALE PAESAGGIO}

Un buon paesaggio deve essere bello e quindi armonioso e ordinato, ma non monotono e deve essere identificativo del luogo e quindi contenere dei caratteri tradizionali 0 anche moderni, ma che con la tradizione hanno continuità e armonia.

Un buon paesaggio del vino deve rendere i caratteri di ruralità intesa 
come equilibrato insieme di naturalezza e presenza antropica, di industriosità, di positività del luogo ove si produce un alimento che nutre lo spirito e la socialità più del corpo.

\section{UN BUON PAESAGGIO ESTESO}

Non basta applicare ai vigneti alcune regole per dare loro un aspetto armonioso: occorre che anche le altre parti di un territorio vinicolo abbiano un aspetto piacevole e identificativo.

Occorre evitare il disordine edilizio, la commistione caotica di edificato e coltivato, la saldatura in un unico continuo edificato di centri e nuclei abitati aventi ognuno propria identità.

Occorre edificare in modo discreto considerando le esigenze di sviluppo di impresa agricola nell'ambito di un progetto aziendale, ma evitando stili, tipologie e volumi dissonanti rispetto al contesto.

Occorre curare l'inserimento paesaggistico delle strade e degli elettrodotti.

Occorre localizzare le cave ove siano meno impattanti e rimodellarle e ripristinarle gradualmente durante le fasi di coltivazione in modo che si armonizzino con il paesaggio circostante.

Occorre mantenere un sistema delle aree naturali e del verde formato da boschi, prati, boschette lungo i corsi d'acqua, filari.

\section{L'ARCHITETTURA RURALE}

Vanno conservati e recuperati gli elementi dell' architettura rurale, segni e radici della cultura contadina.

La nuova edificazione non deve prevaricare le forme e i volumi dell'edilizia rurale, ma armonizzarsi con essa, senza produrre falsi, ma raccordandosi in una continuità culturale. Bisogna evitare un'edilizia sovrabbondante e disneyana, preferendo allo strepito delle forme da luna park e ai volumi fuori scala la dignità di luoghi deputati al piacere della sosta e della meditazione.

\section{IL BUON PAESAGGIO DEI VIGNETI}

Bisogna applicare alla localizzazione e alla realizzazione dei vigneti alcune semplici regole che contemperino le necessità produttive con le esigenze di buon paesaggio.

Le aree da destinare a vigneti vanno definite con un attento studio in sede di redazione di piano regolatore, evitando aree fortemente acclivi e instabili e preservando le superfici boscate di maggior pregio ed i vigneti storici. I vigneti si devono integrare con gli elementi vegetali del paesaggio quali boschetti, siepi e filari. I terrazzamenti devono seguire la forma del terreno e le curve di livello, evitando linee spezzate. Si devono evitare pesanti sbancamenti. Compatibilmente con le esigenze produttive, si devono mantenere gli elementi della morfologia e dell'idrografia, anche evitando di eliminare impluvi e ruscelli e lasciando attorno a questi fasce di vegetazione spontanea. Le scarpate devono avere pendenze non eccessive ed essere rinverdite, evitando in genere la costruzione di muri di sostegno. Si devono evitare inutili artificializzazioni, preferendo pali in legno ai pali in cemento.
Si deve produrre una immagine unitaria del paesaggio del vino unificando i cartelli indicatori e operando affinché le strade del vino percorrano luoghi in cui il paesaggio viene particolarmente curato e caratterizzato.

\section{COSA FARE}

L'Amministrazione regionale può, con il piano territoriale regionale $\mathbf{0}$, in attesa, con un documento tecnico di indirizzo, dettare criteri per la tutela del paesaggio delle aree vinicole.

Può indirizzare gli incentivi economici tenendo conto della qualità ambientale degli insediamenti agricoli e agrituristici.

Può promuovere studi e iniziative per il mantenimento e miglioramento del paesaggio del vino.

Può incentivare la nascita ed il mantenimento delle strade del vino.

Le Province, in base alle loro competenze, possono contribuire alla definizione di un buon assetto del territorio. I Comuni possono, mediante i loro piani regolatori, indirizzare i vigneti nelle aree più vocate, curando gli aspetti paesaggistici. Le Associazioni dei viticoltori devono collaborare con le Amministrazioni competenti per la conoscenza delle Imprese e del territorio e la definizione delle linee di indirizzo. Possono fornire opera di assistenza tecnica per indirizzare i loro soci verso una trasformazione dei loro terreni consona alle esigenze di una produzione moderna e al contempo rispettosa del paesaggio e dell'identità dei luoghi. I Viticoltori possono curare che le trasformazioni del territorio che essi compiono per migliorare ed incrementare i vigneti e gli edifici per la lavorazione del vino, per la sua degustazione, per l'ospitalità e per la ristorazione, seguano criteri di equilibrio paesaggistico.

\section{Hanno partecipato:}

Ivana Adami, presidente del Consorzio colli orientali del Friuli Aldo Bader, presidente dell'ISPAR

Roberto Barocchi, vicepresidente dell'ISPAR, relatore della Carta

Paolo Cecchini, Sindaco di Premariacco

Paolo Corbini, Associazione nazionale Città del vino

Mauro Donda, direttore della Federazione provinciale Coldiretti di Udine

Ida Frigo Fondazione Benetton

Adriano Gigante, vicepresidente del Consorzio colli orientali

Carlo Leonardelli, vicedirettore del Servizio della pianificazione territoriale, Provincia autonoma di Bolzano

Paolo Mattiussi, responsabile del Servizio della programmazione economico territoriale, Regione Emilia Romagna

Eros Mauro, direttore del Servizio delle produzioni vegetali, Regione autonoma Friuli-Venezia Giulia

Antonio Nonino, direttore del Consorzio Ledra Tagliamento

Lucio Saccari, direttore del Servizio della tutela del paesaggio,

Regione autonoma Friuli-Venezia Giulia

Maurizio Trevisan architetto, consulente della Coldiretti

Attilio Vuga, sindaco di Cividale del Friuli

Ornella Zucco, sindaco di Corno di Rosazzo 


\section{APPENDICE 2}

DIRETTIVE PER L'EFFETTUAZIONE DI SBANCAMENTI E RIMODELLAMENTI DEI VERSANTI PER L'IMPIANTO DI VIGNETI ED ALTRE COLTURE ARBOREE SPECIALIZZATE

a cura di Paolo Bazzoffi

\section{A) CONCESSIONE DELL'AUTORIZZAZIONE}

I livellamenti dovranno essere autorizzati dall'autorità competente. Per la concessione dell'autorizzazione dovranno essere presentati i seguenti documenti:

Relazione agronomica contenente:

allegato tecnico che descriva l'attuale utilizzo del suolo allegato tecnico che descriva il futuro utilizzo del suolo

carta plano-altimetrica, corredata da curve di livello con equidistanza $1 \mathrm{~m}$, della situazione dell'area precedente il livellamento.

carta plano-altimetrica, corredata da curve di livello con equidistanza $1 \mathrm{~m}$, della situazione successiva il livellamento.

carta degli spessori di scavo e di riporto, sotto forma di curve di livello ad equidistanza decimetrica (isopache positive per i riporti e negative per gli scavi).

Relazione pedologica di dettaglio (carta dei suoli e relazione pedologica) della situazione precedente il livellamento e di quella successiva, con giudizio sulla fattibilità.

Relazione geologica sulla fattibilità dell'intervento in relazione alle modificazioni indotte sull'idrologia superficiale e profonda, sulla stabilità dei versanti e sugli effetti a distanza. La relazione geologica dovrà fornire il dettaglio dei parametri geotecnici (fra cui l'angolo di attrito dei materiali dopo il rimodellamento e l'angolo di attrito residuale successivo allo scasso profondo e alla successiva lavorazione del suolo).

Dichiarazione di sostenibilità ambientale, ove anche si affermi che i volumi di sterro e di riporto sono stati ridotti al minimo e che non impattano negativamente sulle funzioni del suolo, sul reticolo idrografico e non recano danno ai terreni contermini.

Piano di ripristino e protezione nel quale verrà indicato: a) la zona a lato di quella interessata dal livellamento, per l'accumulo dei materiali terrosi tratti dagli orizzonti superficiali e la modalità della loro ridistribuzione sul suolo livellato. b) le misure che verranno adottate per con- tenere al massimo l'erosione fino all'affermazione dell'inerbimento spontaneo 0 artificiale (applicazione di geo-stuoie, ecc.).

Relazione paesaggistica, che dimostri la l'inserimento armonico dell'impianto e la tutela del paesaggio, contenente:

il rendering dell'area (foto modellazione realistica), con i servizi di visualizzazione, fotoinserimento e Valutazione di impatto Visivo Renderlight, volti ad illustrare il risultato del rimodellamento del versante, all'interno dell'area di intervento, con particolare attenzione a forme, colori e materiali vincolati ai parametri dell'area.

B) PIANO PER L'ESECUZIONE DEL RIMODELLAMENTO E MODALITÀ ESECUTIVE

Gli sbancamenti ed i livellamenti approvati dall'autorità competente dovranno essere attuati in conformità alla documentazione prodotta per l'ottenimento dell'autorizzazione.

Al fine di evitare danni irreparabili ex-post, la direzione dei lavori avverrà alla presenza del geologo che potrà imporre direttive in itinere diverse a quelle di progetto, in relazione all'osservazione in campo di caratteristiche geopedologiche ed idrologiche non rilevate con i saggi effettuati per la stesura della relazione geologica.

Nelle procedure di rimodellamento si dovrà rimuovere e conservare il suolo dell'orizzonte A e, con cumulo a parte, quello sottostante all'orizzonte A facente parte dell'epipedon, per ridistribuirlo in superficie nell'appropriata sequenza, dopo il rimodellamento della pendice. La roccia madre non potrà essere oggetto di livellamento e scasso.

\section{C) OPERAZIONI POST RIMODELLAMENTO}

L'esecutore dei lavori dovrà produrre una relazione tecnica rilasciata dal geologo con allegati grafici alla scala minima di 1:1000, o scala maggiore se necessaria al fine di evidenziare dettagliatamente la zona sulla quale è stato effettuato il livellamento. La relazione dovrà contenere una comparazione fra il risultato visivo raggiunto e la documentazione di foto modellazione realistica presentata precedentemente all' approvazione del progetto.

In caso di mancata rispondenza delle caratteristiche geologiche e/o pedologiche e/o paesaggistiche rispetto a quanto prescritto dall'autorizzazione, l'esecutore delle opere dovrà ripristinare, a proprie spese, lo stato originario dei luoghi, con obbligo di effettuare le opere di consolidamento prescritte dal geologo con opportuna relazione. 